\title{
Proposta de um sistema de avaliação do desempenho para arranjos produtivos locais
}

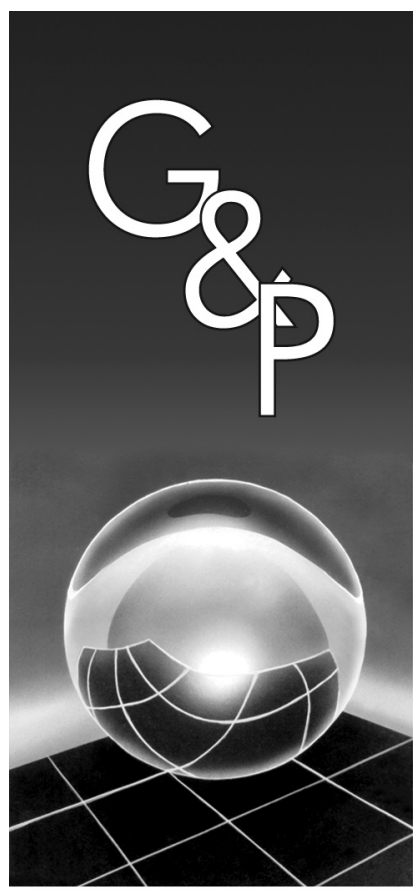

\author{
Edwin Vladimir Cardoza Galdámez \\ Luiz Cesar Ribeiro Carpinetti \\ Mateus Cecílio Gerolamo
}

Resumo

Os Arranjos Produtivos Locais (APLs) são sistemas que podem ser utilizados para promover a cooperação empresarial, a inovação contínua e o desenvolvimento sustentável das Pequenas e Médias Empresas (PMEs). O processo de gestão de desempenho do APL é construído a partir do planejamento estratégico e com a implantação de ações coletivas de melhoria contínua. Também é necessário construir uma infraestrutura local e um ambiente que estimule a confiança e a cooperação dos membros do APL. A avaliação de desempenho é uma prática que fortalecerá a coordenação e execução das atividades de melhoria contínua do APL. Assim, o objetivo deste trabalho é propor um Sistema de Medição do Desempenho (SMD) que dê suporte ao processo de gestão de desempenho do APL. A proposta foi construída a partir das pesquisas de campo realizadas nos APLs de Ibitinga e Jaú. Os resultados demonstram que a medição de desempenho integrada a um processo sistemático de melhoria contínua promove a gestão colaborativa, aprimora o processo de tomada de decisão ou coordenação das ações planejadas pelas instituições, empresas e outros órgãos que fazem parte dos APLs. É um instrumento que pode ajudar a monitorar o desempenho das PMEs inseridas em uma rede de cooperação empresarial e direcionar as iniciativas coletivas ou ações de melhoria para as principais necessidades do APL.

Palavras-chave: Arranjo produtivo local. Sistema de medição de desempenho. Melhoria contínua. Pequenas e médias empresas.

\section{Introdução}

As novas configurações da economia mundial (diminuição das barreiras do comércio internacional, formação de blocos regionais, uso intensivo da tecnologia de informação e do conhecimento, crescimento do setor de serviços, processo de terceirização, fusões, alianças, desintegração vertical das grandes empresas, formação de redes de cooperação empresarial etc.) pressionam as empresas a implantar programas e métodos para melhorar os resultados em várias dimensões críticas de desempenho (custos, qualidade, meio ambiente, inovação tecnológica, produção etc.).

A gestão de desempenho das empresas depende dos recursos organizacionais, tipo de prática utilizada para a melhoria e mudança (sistemas de gestão da qualidade, programa seis sigma, filosofia de produção enxuta, o método de gestão estratégica Balanced Scorecard, Performance Prism etc.), do processo sistematizado de gestão organizacional (GEROLAMO, 2003; CARPINETTI, 2000; CARPINETTI; MARTINS 2001), da qualificação das pessoas, infraestrutura organizacional e do sistema de avaliação (KAPLAN; NORTON, 2001; RENTES et al., 2002).

Pesquisas realizadas no Brasil indicam que essa visão de gestão de negócios dificilmente é implementada nas Pequenas e Médias Empresas (PMEs) (SEBRAE, 2005; AMATO NETO, 2005; VERSCHOORE, 2004; CASSIOLATO; LASTRES, 2003; PUGA, 2003; SUZIGAN, 2001). A carência de um modelo organizacional nas PMEs limita o desenvolvimento industrial, a competitividade dos seus produtos e processos e a tomada de decisão. Aspectos que comprometem o desempenho no mercado, a prática de cooperação empresarial, a participação nas redes de empresas e podem levar até ao encerramento das atividades. Outros obstáculos que 
impedem o crescimento das empresas de pequeno porte são: a falta de acesso ao crédito, as elevadas taxas reais de juros, a concorrência informal, as leis trabalhistas ultrapassadas e a burocracia pública (MENDES, 2005).

Uma tendência dos países é promover o desempenho das PMEs concentradas nas regiões onde prevalece um determinado tipo de negócio ou atividade econômica. O fenômeno de aglomeração de PMEs é denominado na literatura como clusters (PORTER, 2000; NACIONES UNIDAS, 1998; ENRIGHT, 1994). No Brasil, o termo mais comum é o de Arranjo Produtivo Local (APL), publicado pelo Banco Nacional de Desenvolvimento (BNDES) e adotado por diferentes órgãos públicos e privados (SANTOS; GUARNERI, 2000; PUGA, 2003).

É possível destacar que os conceitos, métodos, técnicas e práticas de gestão da produção podem contribuir com o processo de desenvolvimento das PMEs inseridas em APLs (SUZIGAN, 2001). Utilizando essa hipótese como base, o objetivo do trabalho é propor um Sistema de Medição do Desempenho (SMD) para APLs. Especificamente, apresenta-se a estrutura do SMD para arranjos produtivos, as perspectivas de gestão de desempenho e os respectivos indicadores de avaliação de desempenho.

Éummodeloconstruído a partir das pesquisas realizadas nos APLs de Ibitinga - Indústria de Bordados de Cama, Mesa e Banho; e Jaú - Indústria de Calçado Feminino. Nos dois APLs existiam projetos formais de cooperação, promovidos e coordenados por instituições externas e do próprio local (SEBRAE/SINDICALÇADO - APL Jaú) e (SEBRAE/FIESP/SINDICOBI - APL Ibitinga). Durante o desenvolvimento da pesquisa de campo, se verificou que existia uma carência da prática de medição de desempenho no APL e nas PMEs que participavam das iniciativas promovidas pelas instituições. Essa necessidade motivou os pesquisadores a propor e validar um modelo conceitual de medição de desempenho para arranjos produtivos.

Um modelo de SMD pode direcionar o processo de melhoria e mudança das PMEs do APL, promover a gestão colaborativa e aprimorar a tomada de decisão ou a coordenação das ações planejadas pelas instituições, empresas e outros órgãos que fazem parte dos APLs. É um instrumento que pode ajudar a monitorar o desempenho das PMEs inseridas em uma rede de cooperação empresarial e direcionar as iniciativas coletivas ou ações de melhoria para as áreas (recursos humanos, administração financeira, comercial, produção e mercado) com resultados insatisfatórios no APL (GALDAMEZ, 2007).

Na próxima seção, é apresentada uma visão do projeto de pesquisa. Em seguida, descrevem-se os conceitos teóricos e práticos sobre medição de desempenho e APL e apresenta-se o modelo conceitual do SMD para arranjos produtivos. O próximo tópico refere-se às pesquisas de campo realizadas nos APLs de Ibitinga e Jaú. Para finalizar, são discutidos os resultados alcançados com o desenvolvimento e a aplicação da proposta.

\section{Desenvolvimento do projeto de pesquisa}

Os tópicos gerais do projeto de pesquisa são representados na Figura 1. Na primeira fase, foram definidas as principais questões de pesquisa: a prática de avaliação de desempenho dá suporte ao processo de gestão de desempenho do APL, ajuda a coordenar o processo de inovação contínua do APL e pode promover a cooperação empresarial.

$\mathrm{Na}$ Fase II, identificaram-se as referências bibliográficas sobre SMDs, gestão de melhoria e mudança e características dos arranjos produtivos. Nessa fase, também se desenvolveu uma pesquisa de campo no APL de Ibitinga, durante o período de março de 2004 até outubro de 2005. O trabalho de campo foi de caráter exploratório e descritivo (YIN, 2001; GIL, 1999). O método científico descritivo ajudou a definir as principais características (estratégias de negócios, cooperação, governança, spillover, coordenação, confiança etc.) que influenciam o ambiente industrial. Com a pesquisa exploratória, procurou-se definir as perspectivas de gestão de desempenho e identificar o relacionamento e a viabilidade de desenvolver SMDs para APLs. Com esta atividade, foram elencadas (diagnosticadas) as necessidades e as características dos arranjos produtivos e das PMEs. Os dados foram coletados a partir de entrevistas e reuniões com agentes e coordenadores locais, gestores de projeto de desenvolvimento industrial, empresários, responsáveis pelas atividades e administração dos sindicatos, coordenadores de instituições de ensino e prestadores de serviços (empresas de consultoria) do APL. Dados secundários também foram utilizados como fontes da pesquisa de campo.

Em seguida, na Fase III, com a revisão bibliográfica e a pesquisa de campo propôs-se o modelo teórico de SMD para APLs (perspectivas e indicadores de desempenho) e as características do processo de gestão de desempenho para os APLs.

Na Fase IV, uma nova pesquisa de campo foi desenvolvida nos APLs de Ibitinga e Jaú. Considerando as diferenças e semelhanças que existem nos APLs, essa estratégia permitiu validar a proposta e explorar de vários ângulos (diferentes variáveis que influenciam a pesquisa) a teoria de medição de desempenho em APLs (YIN, 2001; ROESCH, 1999; EISENHARDT, 1989).

Essa etapa foi realizada no período de novembro de 2005 até março de 2007, em Ibitinga, e de julho de 2006 até dezembro de 2006, em Jaú. Nos dois arranjos produtivos, o modelo foi integrado ao Projeto de Desenvolvimento de APLs, coordenado pelo convênio SEBRAE/FIESP em 


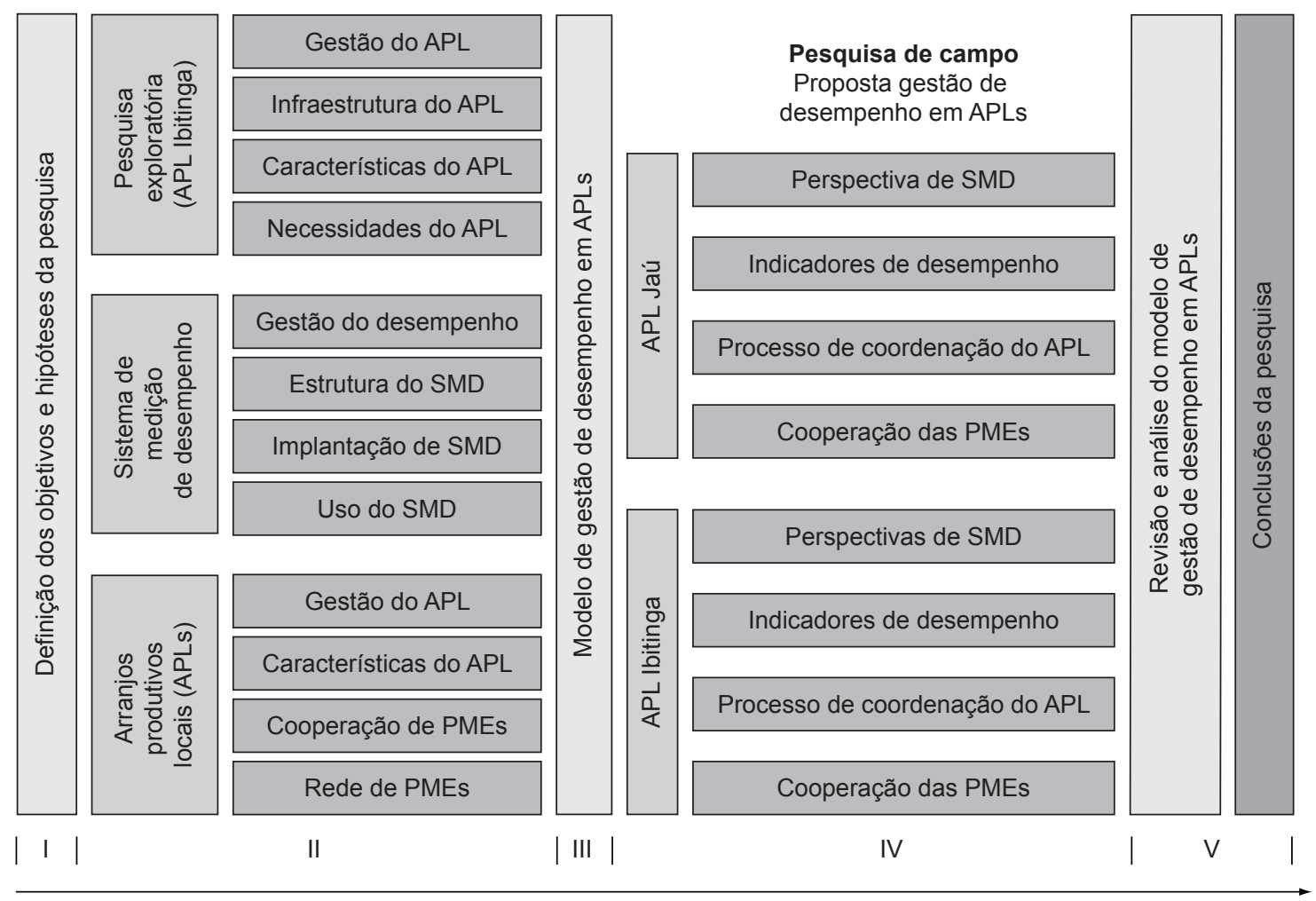

Desenvolvimento da pesquisa

Figura 1. Visão geral do projeto de pesquisa.

Ibitinga e somente pelo SEBRAE em Jaú. Foram projetos executados com as parcerias locais (PMEs, Sindicato das Empresas, Associação Comercial e Prefeitura Municipal) e com outras instituições governamentais (SENAI, CIESP, BNDES, FINEP). Nesta fase foi utilizado o procedimento metodológico de pesquisa-ação (COUGHLAN; COGHLAN, 2002). Trata-se de um método no qual os pesquisadores assumiram um caráter participativo, interagiram com os participantes do projeto e aprenderam simultaneamente.

A Fase V do projeto consiste na análise e revisão do modelo teórico apresentado e utilizado no processo de gestão de desempenho dos APLs Ibitinga e Jaú. Esta etapa permitiu incorporar as mudanças no SMD proposto para APLs.

\section{Medição de desempenho}

A medição de desempenho é um processo utilizado para quantificar a eficiência e eficácia de uma empresa, dos processos de negócio ou das atividades realizadas pelas pessoas (NEELY et al., 1995; LEBAS, 1995). É um método que contribui com o processo de tomada de decisão porque permite quantificar (registrar) a eficiência e eficácia de ações passadas, facilitando o uso da infor- mação (MARTINS, 2002; NEELY, 1998; BITITCI et al., 1997; KAPLAN; NORTON, 1996; KAYDOS, 1991; LEBAS, 1995). Outras características da medição de desempenho são identificadas e avaliadas nos trabalhos publicados por Garengo et al. (2005), Hudson (2001), Martins (1999) e Neely et al. (1995).

Lehtinen et al. (1998) destacam que os quatro princípios mais importantes para construir um processo de medição de desempenho e motivar o uso da informação são: $i$ ) a extensa cooperação das pessoas desde o início até o fim do projeto; ii) integrar as habilidades das pessoas; iii) sistematizar o progresso (desempenho) passo a passo; e $i v$ ) incorporar métodos e ferramentas de melhoria nas rotinas diárias das pessoas.

\subsection{Modelos teóricos de medição de desempenho}

Dentre os novos modelos de SMDs, os que mais se destacam na bibliografia são: o método de definição e seleção de indicadores (ÁLVARO, 2001), Balanced Scorecard (KAPLAN; NORTON, 1996), Performance Prism (NEELY; ADAMS, 2001), Integrated Performance Measurement Systems (BITITCI et al., 1997), a estrutura de indicadores de gestão (MUSCAT; FLEURY, 1992), o Performance Measurement Questionnaire 
(DIXON et al., 1990) e Performance Pyramid (CROSS; LYNCH, 1990).

Cross e Lynch (1990), Dixon et al. (1990) e Muscat; Fleury (1992) destacam que um SMD integrado ilustra a relação hierárquica que existe entre as áreas críticas das operações e os objetivos externos de negócio (baseado nas prioridades dos consumidores). Além disso, demonstram as vantagens que as empresas alcançam no processo de gestão quando os indicadores de desempenho (IDs) (BOURNE, 2002) são integrados à visão estratégica da empresa.

Kaplan e Norton (1996) enfatizam a integração e o agrupamento dos IDs financeiros e não-financeiros em torno de quatro perspectivas de avaliação: a financeira, dos clientes, dos processos de negócio internos e de aprendizado e crescimento da empresa. É comum que as empresas, conforme suas necessidades, utilizem outras perspectivas de gestão de desempenho ou adaptem os princípios básicos deste modelo de gestão. As principais características do modelo são: o BSC é centralizado nos resultados (objetivos estratégicos do negócio), cria uma estrutura de relações de causa-efeito entre os IDs e as perspectivas de avaliação, isso proporciona um método prescritivo para a estrutura do SMD, ressalta o equilíbrio entre o número de IDs que são utilizados na empresa e destaca o processo de aprendizagem (ÁLVARO, 2001).

As principais críticas apresentadas ao BSC são: o modelo de gestão de desempenho falha porque não incorpora métodos para a identificação dos processos críticos ou oportunidades de melhoria relacionadas aos objetivos estratégicos (ÁLVARO, 2001; SCHNEIDERMAN, 1999), não trata sobre o processo de definição das características dos indicadores (SCHNEIDERMAN, 1999), não demonstra claramente como construir a relação entre os indicadores das perspectivas de desempenho, caracterizadas como independentes no modelo (NORREKLIT, 2000) e não promove a participação do usuário da informação no processo de desenvolvimento da medição de desempenho (HUDSON, 2001).

Bititci et al. (1997) recomendam construir o SMD a partir de níveis organizacionais: de negócio, das unidades de negócio, dos processos de negócio e das atividades. Para cada nível da pirâmide, são identificados os requisitos dos stakeholders, os objetivos e, a partir disto, são desdobrados e integrados os IDs da empresa.

Martins (1999) destaca que, considerando somente essa visão, é fortalecida apenas a integração vertical entre os níveis, pois nenhuma consideração é apresentada para a integração horizontal, principalmente, nos processos de negócio e das atividades. Hudson (2001) apresenta outra crítica relacionada ao processo de estruturação: o método não apresenta objetivos específicos e nem uma escala de tempo para o desenvolvimento e execução do projeto de SMD.
Neely e Adams (2001) propõem cinco perspectivas interligadas e ilustradas pelas faces de um prisma para um SMD: satisfação dos stakeholders; estratégias; processos; capacidades e contribuição dos stakeholders. Os stakeholders podem ser representados por uma pessoa ou um grupo de pessoas que tem um relacionamento formal com o negócio. A capacidade é definida como a combinação de pessoas, práticas, tecnologias e a infraestrutura da empresa, aspectos que coletivamente criam valor para seus stakeholders a partir das atividades integradas dos processos gerenciais e operacionais, alinhadas com a estratégia da empresa (NEELY; ADAMS, 2001).

Os elementos que determinam o uso do SMD são: a capacidade da empresa para satisfazer as expectativas dos clientes (resultados), a capacitação das pessoas, os recursos financeiros disponíveis, a forma de coletar as informações, os métodos de processamento de informações e meios utilizados para distribuir e armazenar as informações (MARTINS, 2002; HUDSON, 2001; VAN AKEN et al., 2001; NEELY, 1998; KAPLAN; NORTON, 1996).

\subsection{Medição de desempenho nas pequenas e médias empresas}

$\mathrm{Na}$ bibliografia de SMDs, o porte da empresa é tratado de uma forma genérica. Percebe-se que ainda é reduzido o número de publicações que descrevem, especificamente, as características dos SMDs para PMEs (GARENGO et al., 2005; HUDSON, 2001; LAITINEN, 2002).

Na pesquisa realizada por Hudson (2001), é destacado que várias características propostas pelos modelos de SMDs não estão presentes no processo de gestão de desempenho das PMEs, i.e., as métricas derivam da estratégia da empresa; as métricas de desempenho são definidas e propostas claramente; retratam os resultados alcançados e asseguram o feedback; integram as metas estratégicas com as operações; e estimulam a melhoria contínua. Poucas empresas percebem os benefícios que são alcançados com a medição de desempenho e é comum nas PMEs não possuir um sistema formal de gestão empresarial (GARENGO et al., 2005; HUDSON, 2001). Sousa et al. (2006) apresentam um estudo similar e também concluíram que existe uma diferença entre a teoria e a prática da medição de desempenho realizada pelas PMEs.

Sousa et al. (2006), Garengo et al. (2005), Laitinen, (2002) e Lehtinen et al. (1998) destacam que um SMD para PMEs é construído a partir de um processo sistemático de melhoria contínua e deve-se procurar usar com facilidade, e construí-lo com um número pequeno de IDs. Hudson (2001) sugere que na fase de implantação do SMDs, as PMEs devem destinar recursos humanos 
e financeiros específicos, criar um processo dinâmico, flexível e compatível com as próprias limitações.

Por outro lado, pode-se entender que as PMEs inseridas em redes de cooperação e Arranjos Produtivos Locais posicionam-se em uma melhor situação para a prática sistemática da medição de desempenho, ainda que não seja possível num primeiro momento no âmbito individual de cada empresa, mas sim na medição de desempenho do APL como um todo. Por essa razão, o tópico a seguir retrata a importância desse fenômeno de aglomeração de empresas ou clusters industriais.

\section{Arranjo produtivo local}

$\mathrm{Na}$ bibliografia, são apresentados vários conceitos sobre o fenômeno de agrupamento ou aglomerações de empresas, também denominado de clusters industriais (PORTER, 1998), sistemas produtivos e inovativos locais (CASSIOLATO; LASTRES, 2003), arranjos produtivos locais (CASSIOLATO; LASTRES, 2003; SANTOS; GUARNERI, 2000), distritos industriais (SCHMITZ; MUSYCK, 1994), aglomerações industriais (NACIONES UNIDAS, 1998). Suzigan et al. (2004) citam que as distinções conceituais que surgem na bibliografia sobre sistema de produção local resumem-se a graus variados de desenvolvimento, de integração da cadeia produtiva, de articulação e interação entre agentes e instituições locais, e de capacidades sistêmicas para a inovação.

Para o Banco Nacional de Desenvolvimento (BNDES), os APLs são:

[...] definidos como um fenômeno vinculado às economias de aglomeração, associadas à proximidade física das empresas fortemente ligadas entre si por fluxos de bens e serviços. A concentração geográfica permite ganhos mútuos e operações mais produtivas. Entre os aspectos que devem ser observados, destaca-se o papel de autoridades ou instituições locais para a organização e a coordenação das empresas, pois apenas um grupamento de empresas não é suficiente para ganhos coletivos. (SANTOS; GUARNERI, 2000).

Puga (2003) destaca que, na maioria dos casos, em um APL participa um número significativo de PMEs, acrescentando efeitos distributivos, em termos patrimoniais e de emprego, às dimensões setorial e regional. Outra característica relevante dos APLs é "a existência de capital social, definido como grau de cooperação e confiança entre as empresas e as instituições integrantes do APL" (PUGA, 2003).

A cooperação é um instrumento que permite incorporar as PMEs em uma rede, promover o ciclo de inovação tecnológica e determina os resultados do processo de melhoria de um aglomerado de PMEs. Conforme Cassio- lato e Lastres (2003), a cooperação empresarial pode ocorrer por meio de um intercâmbio sistemático de informações produtivas, tecnológicas e mercadológicas (com clientes, fornecedores, concorrentes e outros); interação de vários tipos, envolvendo empresas e outras organizações, por meio de programas comuns de treinamento, realização de eventos/feiras, cursos e seminários, entre outros; e pela integração de competências, por meio da realização de projetos conjuntos, incluindo desde melhoria de produtos e processos até desenvolvimento e pesquisa propriamente dita, entre empresas e destas com outras organizações.

Para Olave e Amato Neto (2000), um APL acumula vários tipos de conhecimento (tácito, explícito e científico) e o acesso é garantido para as PMEs que estão concentradas geograficamente. Essa característica ocorre porque os relacionamentos pessoais e os laços que existem na comunidade (frequentar o mesmo clube, igreja, escola etc.) promovem a confiança e facilitam o fluxo de informações, desenvolvendo com isso uma capacidade tecnológica e de produção no local/região. Criando, com isso, um estoque de recursos humanos especializados.

Segundo Amato Neto (2000), APL é um modelo voltado para uma maior cooperação entre empresas. Parte-se do princípio de que as empresas, principalmente as PMEs, operando em determinada cadeia produtiva e região, oferecem elementos originais para a elaboração de políticas industriais.

Humphrey e Schmitz (2000) acrescentam e examinam outros elementos críticos que influenciam o crescimento das PMEs nos aglomerados industriais e/ou em uma rede de PMEs: a forma de coordenar as ações de melhoria e atividades industriais, o nível de relacionamento e confiança que emerge entre as empresas. Existem diversas estruturas de governança ou formas de coordenação das atividades industriais que são realizadas entre as empresas, as empresas e os agentes locais, e as empresas e seus clientes, com o objetivo de reduzir os custos derivados das transações comerciais (HUMPHREY; SCHMITZ, 2000; STORPER; HARRISON, 1991; WILLIAMSOM, 1985).

\subsection{Vantagens competitivas derivadas dos arranjos produtivos locais}

Segundo Schmitz (1999), as PMEs podem obter ganhos de eficiência a partir da aglomeração. Tais benefícios são alcançados a partir do conceito de eficiência coletiva, definido como a vantagem competitiva derivada de economias externas locais e das ações conjuntas (joint action) (SCHMITZ, 1995). As ações conjuntas são divididas em dois tipos: empresas individuais cooperando e grupos de empresa unindo forças em associações de negócios, consórcio de produtores, e outros semelhantes. Além dessa distinção, pode-se separar entre cooperação 
horizontal e cooperação vertical (SCHMITZ, 1999). Os benefícios que as PMEs alcançam quando estão inseridas dentro dessa visão de redes de cooperação empresarial são apresentados por Pyke ([199-]).

Porter (1998) descreve que as vantagens competitivas das PMEs são associadas sistematicamente ao tamanho, idade, setor, níveis de habilidades e ao ambiente no qual são localizadas, e influenciadas por quatros aspectos:

a) condições dos fatores internos e externos do aglomerado - como a disponibilidade de habilidades, infraestrutura, capital, inovação e empreendedorismo;

b) condições de exigência - desenvolvimento de produto, estrutura da indústria, sistemas locais de compras e distribuição, tamanho do mercado e aglomeração;

c) indústrias relacionadas e de suporte - a presença de fornecedores e clientes que são também firmas mais avançadas, incluindo empresas de serviços; e

d) estratégia de negócio, estrutura e competição afetando como firmas são organizadas, criadas, gerenciadas, competem ou cooperam umas com as outras, incluindo estruturas institucionais e o papel do governo.

Para Humphrey (2003), a competência de inovação e melhoria, está contida dentro de um arranjo produtivo. Em particular, o fato de que essa competência está baseada em conhecimento não decifrável, confiança e estruturas institucionais difíceis de replicar, significa que isso não está disponível para muitos competidores potenciais. Portanto, esse conhecimento localizado se torna ainda mais importante para o próprio desenvolvimento sustentável das PMEs.

Pesquisas destacam que nos APLs há uma necessidade de melhorar vários elementos competitivos: os processos gerenciais, a capacitação dos recursos humanos, a tecnologia, os equipamentos, o marketing, a distribuição, os processos produtivos etc. (CASSIOLATO; LASTRES, 2003; PUGA, 2003; SUZIGAN, 2001).

Isto significa que simplesmente a concentração das PMEs não traz vantagens competitivas coletivas, é necessário promover ações conjuntas que impulsionem as vantagens locais das empresas e promovam a cooperação vertical e horizontal no aglomerado. Uma política de apoio influi decisivamente na redução dos custos de produção, melhoria do produto/processo, desenvolvimento local, expansão industrial etc.

Pensando nessas questões, Meyer-Stamer (2001) e Suzigan (2001) propõem várias políticas de promoção para aumentar as vantagens competitivas derivadas da concentração de PMEs. Entretanto, o principal desafio é determinar como as ações de um nível macro da economia são levadas e implantadas nas redes de cooperação de PMEs dos APLs. Para está problemática, Gerolamo et al. (2008) e Gerolamo et al. (2005) propõem uma abor- dagem conceitual para a estruturação do processo de gestão de melhoria e mudança em redes de cooperação de pequenas e médias empresas, que deverá ser integrado com as ferramentas e métodos de qualidade e gerenciado/ avaliado a partir de um SMD.

\section{Processo de gestão de desempenho de arranjos produtivos locais}

O processo de gestão de desempenho do APL pode caracterizar-se a partir do planejamento de estratégias de desenvolvimento sustentável para a região. É operacionalizado com a implantação de métodos de melhoria e mudança (ações cooperadas) que promovem o desempenho do arranjo produtivo e o capital social. Demanda uma infraestrutura de cooperação e um processo de avaliação de desempenho para tomar as decisões e promover o processo de inovação contínua (GEROLAMO et al., 2008). A avaliação de desempenho é uma ferramenta que permite desenvolver um plano de ações a partir das necessidades dos gestores (stakeholder's) do APL. Além disso, pode incentivar o benchmarking entre as PMEs, e permite coordenar, a partir dos resultados alcançados, as ações de melhoria nas áreas críticas do APL, criando um círculo positivo de controle (SOUZA et al., 2006).

$\mathrm{O}$ gerenciamento local eficiente e a disponibilidade de estruturas de apoio são essenciais para conduzir as empresas em uma via de competitividade robusta. Deve-se desenvolver a inovação constante, qualidade de produtos, flexibilidade funcional e condições de trabalho adequadas para a mão-de-obra local, como base para a competitividade. Assim, neste âmbito, é indispensável que as empresas se re-estruturem e invistam no desenvolvimento tecnológico para enfrentar as mudanças que ocorrem no ambiente industrial e mercadológico em que estão inseridas (KRUGMAN, 1991; NACIONES UNIDAS, 1998).

A Figura 2, ilustra um modelo de referência para o processo de gestão de desempenho de APLs (GEROLAMO et al., 2008). Neste contexto, a avaliação de desempenho do arranjo produtivo assumirá as seguintes características: derivar da estratégia competitiva do APL construída pelo stakeholders, promover a integração das metas estratégicas do APL com os processos de negócio das PMEs, monitorar as áreas críticas de desempenho e dar suporte ao processo de coordenação da melhoria contínua das PMEs. É uma prática que ajuda a gerenciar as informações e assegurar o feedback dos resultados para os gestores do APL ou agentes de governança local (stakeholders). No processo de gestão de desempenho, é imprescindível utilizar uma infraestrutura institucional e construir uma base de confiança e cooperação entre as PMEs e as instituições que participam do desenvolvimento competitivo do APL (GEROLAMO et al., 2008). Isto é, a partir do momento que a cooperação e a 
confiança são inseridas nos participantes de um projeto de desenvolvimento econômico e industrial regional, é possível promover um processo de inovação contínua no arranjo produtivo. Tais elementos são construídos a partir do estabelecimento de acordos bilaterais de cooperação (fornecedor-cliente), formação de grupos de empresários para coordenar ações coletivas, identificação das competências internas do APL etc.

\subsection{Proposta do sistema de medição de de- sempenho para arranjos produtivos locais}

Um programa de desenvolvimento local demanda a articulação, cooperação, confiança e coordenação dos atores locais, o planejamento de ações de melhoria contínua para as áreas ou lacunas de desempenho do arranjo produtivo e a avaliação dos resultados. Tais elementos formam a base para a gestão de desempenho do APL. Meyer-Stamer e Harmes-Liedtke (2005) descrevem que a avaliação de desempenho é um instrumento importante para o processo de aprendizagem em termos de gestão de desempenho dos aglomerados. Nos APLs do Brasil, a avaliação de resultados ou a medição de desempenho não é uma prática comum no gerenciamento do processo de inovação, isto vem comprometendo a eficiência das ações e o uso dos recursos financeiros e humanos, entre outros aspectos (GALDAMEZ, 2007). Também existe um número pequeno de pesquisas sobre o tema (MEYER-STAMER; HARMES-LIEDTKE, 2005; SÖVELL et al. 2003). Todos esses aspectos motivaram os pesquisadores a elaborar a proposta e contribuir com o debate do tema no meio científico e empresarial. O modelo também foi construído a partir dos conceitos destacados pela literatura que pesquisa a prática de medição de desempenho e arranjos produtivos locais, conforme apresentado anteriormente.

As perspectivas de desempenho propostas para gerenciar o processo de inovação contínua do APL são ilustradas pela Figura 3, conforme são descritas, a seguir.

a) perspectiva econômica/social: considera os resultados da economia local (arrecadação de imposto, número de empresas formais e informais etc.), a ocupação dos trabalhadores (número de pessoas com carteira de trabalho assinada) e a capacitação de recursos humanos locais;

b) perspectiva do meio ambiente: é uma perspectiva utilizada para mensurar os impactos ambientais decorrentes do sistema produtivo das PMEs do APL: desperdício de matéria-prima, resíduos, consumo de energia, água etc.;

c) perspectiva do desempenho das PMEs: descreve o crescimento (produtividade, número de vendas etc.) e a competitividade (redução dos custos totais da empresa, valor agregado pelos funcionários etc.) das PMEs do APL. Nesta perspectiva são utilizados indicadores de desempenho financeiros e não-financeiros para avaliar o desempenho nas áreas críticas das PMEs. Recomenda-se, portanto um número reduzido de indicadores nesta perspectiva, visto que depende do esforço e investimento individual de cada empresa;

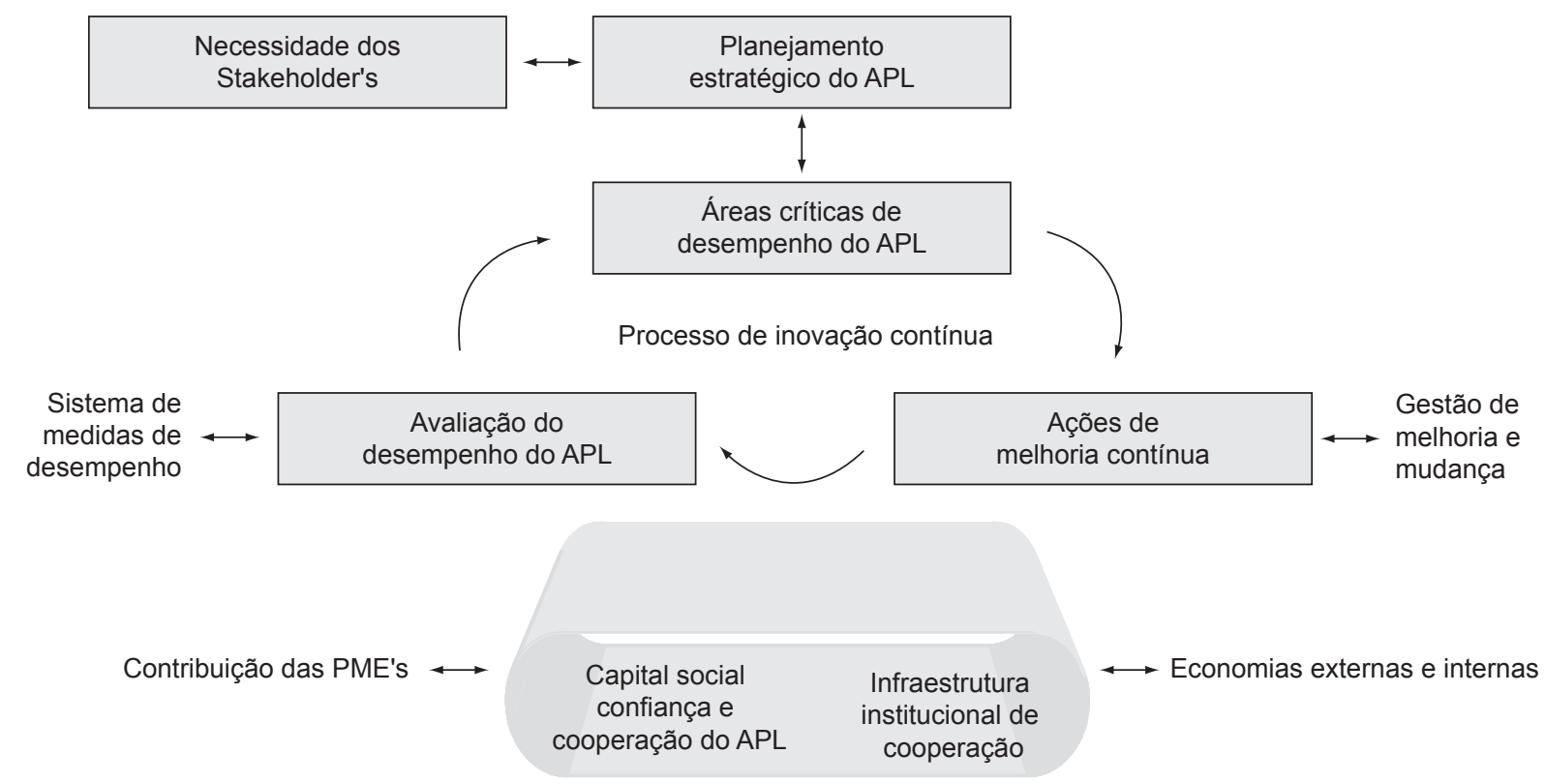

Figura 2. Modelo de gestão de desempenho para APL's. 


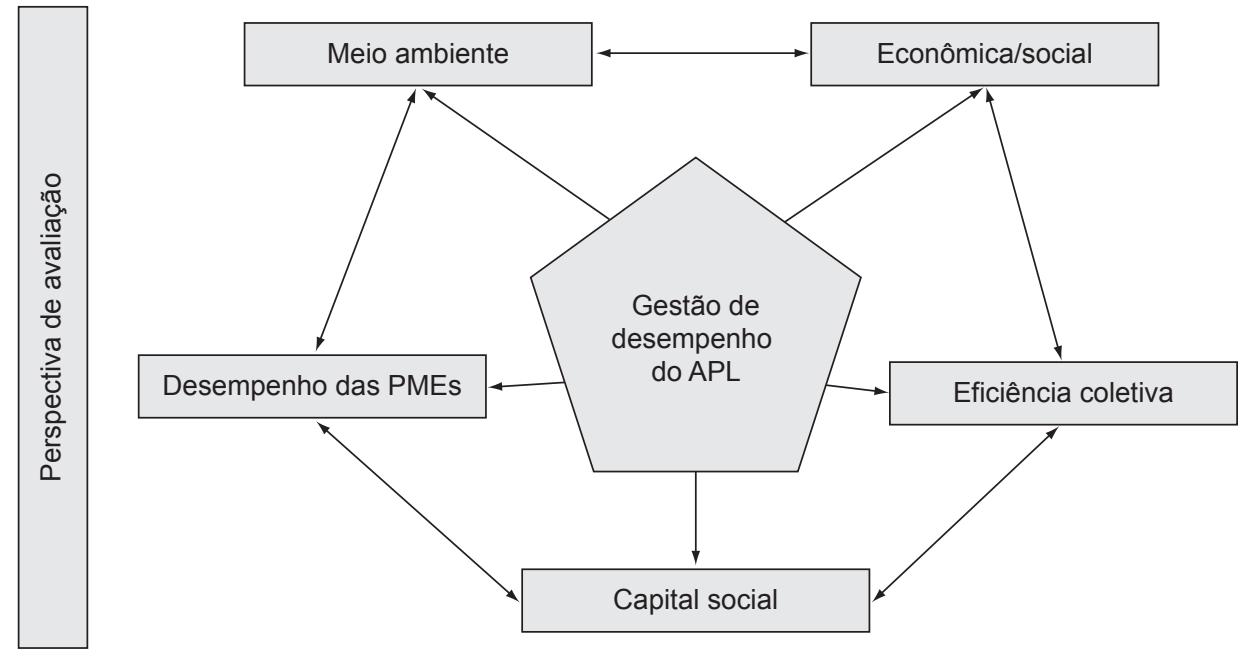

Figura 3. Perspectivas de gestão do SMD para APLs.

d) perspectiva da eficiência coletiva: têm o objetivo de reunir informações sobre os resultados (ganhos coletivos) alcançados pelas PMEs a partir das ações coletivas que são planejadas e executadas no APL;

e) perspectiva do capital social: avalia o nível de confiança e cooperação praticado pelas PMEs. A proposta é utilizar indicadores relacionados aos projetos de cooperação do APL.

No processo de desenvolvimento e implantação do SMD, é necessário estabelecer um conjunto de normas (termo de compromisso do uso da informação), métodos estatísticos de análise dos dados, infraestrutura (procedimentos utilizados para divulgar a informação, disponibilidade de recursos humanos para reunir e analisar os dados etc.) e ferramentas (desenvolvimento de um portal de benchmarking, uso de planilhas etc.) adequadas para garantir a coleta e manutenção dos ID's. Recomenda-se utilizar um framework de desenvolvimento do projeto de SMD (RENTES et al. 2002; ÁLVARO, 2001; Van AKEN et al. 2001; Neely et al. 1997; Kaplan e Norton, 1996; Dixon et al. 1990; Cross e LYNCH, 1990). Isso integra as perspectivas de avaliação e o nível de confiança da medição de desempenho (coleta de informações) realizada no APL.

\section{Desenvolvimento do sistema de medição de desempenho em arranjos produtivos locais}

\subsection{Arranjo produtivo local de lbitinga - indús- tria de cama, mesa e banho}

A cidade de Ibitinga está localizada no interior do Estado de São Paulo, com uma população de aproxi- madamente 50 (Cinquenta) mil habitantes. Os dados históricos da cidade demonstram que a aglomeração das PMEs iniciou na década de 1960, ocorrendo um crescimento significativo no período de 1980 até 1990. $\mathrm{Na}$ região percebe-se que várias economias externas (vantagens) derivam da própria aglomeração de PMEs, dentre as quais se destacam: formação de mão-de-obra especializada (SENAI, Centro Paula Souza, SEBRAE); instalação de fornecedores de matéria-prima e serviços especializados; e melhorias na infraestrutura da cidade para os clientes que visitam a cidade.

No APL (arranjo produtivo local) Ibitinga existem aproximadamente 586 PMEs formais, classificadas na atividade de fabricação de produtos têxtil, especificamente, para o uso e decoração de cama, mesa e banho, atividade industrial que corresponde ao código CNAE 17.61-2 (IBGE, 2003). Com o objetivo de promover a produtividade das empresas, reduzir os custos operacionais e aumentar a qualidade dos produtos das PMEs, a FIESP e o SEBRAE, em 2004, promoveram um projeto de cooperação formal, inicialmente, com 19 empresas do APL. Na coordenação das ações de melhoria também participava o Sindicato das Indústrias e Comércio de Bordados de Ibitinga (SINDICOBI). Além disso, foi o agente local responsável pela infraestrutura necessária para a execução das atividades do projeto do APL Ibitinga. Os principais resultados dessa fase foram o diagnóstico do APL, a definição das características de mercado, a capacitação de funcionários e o incentivo para participar de feiras de negócios nacionais.

A segunda fase do projeto foi iniciada em março de 2005 e concluída em Março de 2007. Nesta etapa, 4 empresas do grupo da Fase I não continuaram por razões particulares (pouco tempo para participar das reuniões e 
os resultados do projeto não foram satisfatórios), porém, 21 novas PMEs foram inseridas, formando com isso um grupo de 36 PMEs.

No APL Ibitinga, entre as principais ações executadas, destacam-se: consultoria nas áreas de finanças, custos industriais, produção, recursos humanos e vendas; contratação de assessorias profissionais nas áreas de moda, design industrial e comércio internacional; registros da marca de "Bordados de Ibitinga"; criação do site do SINDICOBI (www.sindicobi.com.br); treinamento e capacitação de mão-de-obra local; projeto de missões empresariais e participação de feiras; projeto de cooperação da saúde do trabalhador de bordados; desenvolvimento do portal de benchmarking; e projeto de compra coletiva de matéria-prima. Nos projetos de cooperação, outras instituições atuam como parceiras: USP/EESC, ABIT, ParqTec, UNIMED, Prefeitura Municipal e o SENAI.

A Figura 4, ilustra o processo de melhoria do APL Ibitinga executado pelos coordenadores do projeto FIESP/SEBRAE/SINDICOBI. Neste contexto, a estratégia utilizada pelos pesquisadores para implantar os indicadores de desempenho foi dividida em seis etapas: i) Diagnóstico da medição de desempenho; ii) Desenvolvimento de atividades para motivar o capital social do cluster; iii) Definição dos objetivos de desempenho do aglomerado; iv) Elaboração do projeto de medição de desempenho para o APL e PMEs; $v$ ) Prática do benchmarking e revisão do plano de ações de inovação contínua.

Com a pesquisa de campo, percebeu-se que, além de mensurar o desempenho coletivo das PMEs e a economia local, necessitava-se avaliar os resultados alcançados com os projetos de cooperação (eficiência coletiva) e o nível de confiança e a cooperação das PMEs (capital social). Ainda, existia uma necessidade de controlar o processo de implantação das ações de melhoria e planejar novas iniciativas para alavancar o desempenho coletivo das PMEs. Outro aspecto positivo para o desenvolvimento da pesquisa foi que entre os participantes existia um ambiente de cooperação e confiança propício para o processo de gestão de desempenho do APL de Ibitinga. Isto facilitou a implantação da proposta elaborada pelos pesquisadores.

\subsubsection{Processo de medição e avaliação de de- sempenho no arranjo produtivo local de Ibitinga}

No APL (arranjo produtivo local) Ibitinga, o programa de medição de desempenho teve início em novembro de 2005. Nesse período, foi organizado um encontro com 27 empresas que participam do projeto de cooperação do convênio SEBRAE/FIESP/SINDICOBI, foram apresentadas as características do SMD e estabelecido um termo de cooperação e ética sobre as informações utilizadas durante a execução do projeto de pesquisa. No final da reunião, $26 \mathrm{PMEs}$ apoiaram a proposta e assinaram o termo de cooperação. Durante o desenvolvimento da pesquisa, os pesquisadores receberam o apoio dos coordenadores do projeto APL Ibitinga e colaboraram, principalmente, no processo de coleta e análise de dados.

No início do desenvolvimento da proposta, estabeleceu-se um consenso sobre o objetivo do processo de medição de desempenho: mensurar e avaliar os resultados alcançados com a implantação das ações de melhoria, executadas a partir do projeto de cooperação do APL. Além disso, definiu-se que o SMD direcionaria o processo de melhoria contínua do arranjo produtivo e influenciaria o processo de tomada de decisão dos empresários, agentes locais e coordenadores do projeto. Nesta fase inicial, se destacou que a medição de desempenho representava um passo essencial para avaliar os resultados alcançados com a implantação e a coordenação de ações coletivas e projetos de cooperação. Além de ajudar na gestão de desempenho do cluster, o sistema de medição de desempenho tornaria-se-ia um instrumento para reunir informações confiáveis sobre o cluster de Ibitinga.

No processo de desenvolvimento do sistema, foram realizados encontros para definir as metas, as perspectivas de gestão de desempenho dos APLs, os respectivos IDs, o período de coleta e o responsável para coletar os dados, calcular os IDs e apresentar as informações. O Quadro 1 apresenta os IDs associados ao processo de gestão de desempenho do APL Ibitinga. Tais IDs foram escolhidos pelos seguintes motivos: i) para avaliar os resultados alcançados com o programa de desenvolvimento regional (Projeto de Cooperação Empresarial); ii) fortalecer o processo de tomada de decisão dos atores de governança

\begin{tabular}{|c|c|c|c|c|c|c|}
\hline & \multicolumn{5}{|c|}{ Processo sistemático de melhoria e mudança no APL } & \\
\hline & Diagnóstico & Planejamento & Implantação & Resultados & Avaliação & \\
\hline \begin{tabular}{|l|} 
Identificação e \\
formação de \\
grupos de \\
PMEs \\
\end{tabular} & \begin{tabular}{|l|} 
Identificação \\
das lacunas de \\
desempenho do \\
APL \\
\end{tabular} & \begin{tabular}{|l|} 
Planejamento \\
estratégico das \\
necessidades \\
coletivas das PMEs
\end{tabular} & $\begin{array}{l}\text { Execução do plano de ações } \\
\text { do APL: capacitação, } \\
\text { pesquisa, feiras, ações } \\
\text { coletivas, etc. }\end{array}$ & $\begin{array}{l}\text { Coleta de dados } \\
\text { das ações } \\
\text { implantadas }\end{array}$ & \begin{tabular}{|l|} 
Monitoração \\
dos resultados \\
alcançados no \\
APL \\
\end{tabular} & $\begin{array}{l}\text { Ações de melhoria } \\
\text { e mudança das } \\
\text { PMEs }\end{array}$ \\
\hline
\end{tabular}

Figura 4. Processo sistemático de melhoria e mudança no APL. 
local (SEBRAE/FESIP/SINDICOBI); iii) desenhar o contexto econômico da atividade industrial (pessoas ocupadas, pessoas qualificadas, produtividade, lucratividade, custo total e preço médio de venda); $i v$ ) promover a cooperação e coordenação do processo de inovação contínua; v) estimular o benchmarking das PMEs; e vi) justificar a solicitação de novos investimentos para o desenvolvimento regional. As métricas de desempenho também foram definidas em função da capacidade das empresas fornecerem a informação das variáveis.

Considerando-se que a prática de medição de desempenho era inovadora no cluster de Ibitinga, principalmente, nas firmas de pequeno porte, também foram adotados alguns princípios (GARENGO et al., 2005; HUDSON, 2001; MARTINS, 1999): implantar um número reduzido de métricas de desempenho, simplicidade para calcular e analisar os resultados, reduzir o nível de dificuldade para coletar as variáveis do sistema de medição de desempenho do cluster e utilizar métricas de desempenho que agregam valor ao processo de tomada de decisão dos agentes e, principalmente, empresas do cluster de Ibitinga.
O indicador de desempenho, preço médio de venda dos produtos representa a capacidade das empresas agregarem valor aos produtos e o poder de negociação do valor econômico dos produtos com os clientes. Esse indicador ajuda a selecionar os produtos que têm maior impacto na lucratividade e, com essa informação, os empresários podem construir uma estratégia de comercialização e produção. A produtividade e eficiência do APL são avaliadas em termos de valor adicionado pelas pessoas ocupadas (VA/PO) e custo total da empresa negócio. Os resultados dos indicadores de desempenho ajudam a discutir as práticas de gestão de operações e estratégias de gestão de estoques que reduzem o desperdício de matéria-prima. Além disso, as informações fornecem um panorama da situação econômica das empresas do cluster. Para avaliar os resultados econômicos e sociais, foram propostos os indicadores: pessoas qualificadas e pessoas ocupadas. Tais indicadores de desempenho retratam o desenvolvimento regional e desenham um panorama da formação dos recursos humanos do local.

Os resultados também são avaliados conforme o desempenho econômico do cluster. Para avaliar a dimensão de

Quadro 1. Indicadores de desempenho do APL Ibitinga.

\begin{tabular}{|c|c|c|c|c|c|c|c|}
\hline $\begin{array}{l}\text { Perspectiva } \\
\text { de } \\
\text { desempenho }\end{array}$ & $\begin{array}{c}\text { Indicadores } \\
\text { de } \\
\text { desempenho }\end{array}$ & Objetivo & Meta & $\begin{array}{l}\text { Método } \\
\text { de } \\
\text { cálculo }\end{array}$ & Unidade & $\begin{array}{c}\text { Frequência } \\
\text { da } \\
\text { medida }\end{array}$ & Resp. \\
\hline \multirow{4}{*}{$\begin{array}{l}\text { Desempenho } \\
\text { das } \\
\text { empresas }\end{array}$} & $\begin{array}{l}\text { Preço médio de } \\
\text { venda dos produtos }\end{array}$ & $\begin{array}{l}\text { Aumentar o valor } \\
\text { do mercado }\end{array}$ & $10 \%$ & $\begin{array}{l}\text { Faturamento bruto/ } \\
n^{\circ} \text { de peças vendidas }\end{array}$ & $\mathrm{R} \$ /$ peça & semestral & \\
\hline & $\begin{array}{l}\text { Valor adicionado } \\
\text { pelas pessoas } \\
\text { ocupadas }(\mathrm{PO})\end{array}$ & $\begin{array}{l}\text { Melhorar a } \\
\text { produtividade }\end{array}$ & $15 \%$ & $\begin{array}{l}\text { Valor adicionado/ } \\
\mathrm{n}^{\mathbf{o}} \text { de pessoas }\end{array}$ & $\mathrm{R} \$ / \mathrm{PO}$ & semestral & \\
\hline & $\begin{array}{l}\text { Custo total da } \\
\text { empresa negócio }\end{array}$ & $\begin{array}{l}\text { Reduzir os custos } \\
\text { das empresas }\end{array}$ & $3 \%$ & $\begin{array}{l}\text { Custo total da empresa/ } \\
\text { faturamento bruto } \\
\text { da empresa }\end{array}$ & $\%$ & semestral & 党 \\
\hline & $\begin{array}{l}\text { Lucratividade } \\
\text { das PMEs }\end{array}$ & $\begin{array}{l}\text { Aumentar o } \\
\text { ganho obtido } \\
\text { sobre a receita } \\
\text { bruta das empresas }\end{array}$ & $8 \%$ & $\begin{array}{l}\text { Lucro líquido/ } \\
\text { receita total da } \\
\text { empresa }\end{array}$ & $\%$ & semestral & $\begin{array}{l}\frac{1}{1} \\
0 \\
\frac{0}{0} \\
0 \\
\frac{0}{2} \\
0 \\
\frac{0}{0}\end{array}$ \\
\hline \multirow[t]{2}{*}{$\begin{array}{l}\text { Resultados } \\
\text { econômicos } \\
\text { e sociais }\end{array}$} & $\begin{array}{l}\text { Pessoas } \\
\text { ocupadas }\end{array}$ & $\begin{array}{l}\text { Incentivar a } \\
\text { contratação de } \\
\text { pessoas no APL } \\
\text { Ibitinga }\end{array}$ & $7 \%$ & $\begin{array}{l}\text { Pessoas ocupadas nas } \\
\text { empresas do projeto } \\
\text { APL Ibitinga }\end{array}$ & pessoas & semestral & $\begin{array}{l}\frac{\infty}{3} \\
\frac{0}{0} \\
\stackrel{0}{0} \\
\stackrel{0}{0}\end{array}$ \\
\hline & $\begin{array}{l}\text { Pessoas } \\
\text { qualificadas }\end{array}$ & $\begin{array}{l}\text { Capacitar a } \\
\text { mão-de-obra } \\
\text { local }\end{array}$ & 300 p. & $\begin{array}{l}\text { Pessoas treinadas no } \\
\text { projeto APL Ibitinga }\end{array}$ & pessoas & mensal & 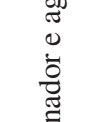 \\
\hline $\begin{array}{l}\text { Eficiência } \\
\text { coletiva }\end{array}$ & $\begin{array}{l}\text { Compra } \\
\text { coletiva de fibra }\end{array}$ & $\begin{array}{l}\text { Reduzir os custos } \\
\text { e promover a } \\
\text { cooperação entre } \\
\text { os empresários }\end{array}$ & $\begin{array}{l}30 \\
\text { ton. }\end{array}$ & $\begin{array}{l}\text { Soma do pedido } \\
\text { realizado pelas PMEs } \\
\text { do projeto APL } \\
\text { Ibitinga }\end{array}$ & ton/mês & mensal & $\begin{array}{l}\frac{u}{0} \\
\dot{0} \\
0 \\
0\end{array}$ \\
\hline $\begin{array}{l}\text { Capital } \\
\text { social }\end{array}$ & $\begin{array}{l}\text { Porcentagem de } \\
\text { empresas envolvidas } \\
\text { nas ações de } \\
\text { cooperação }\end{array}$ & $\begin{array}{l}\text { Aumentar o } \\
\text { número de } \\
\text { participantes }\end{array}$ & $50 \%$ & $\begin{array}{l}\text { Total de PMEs que } \\
\text { participam de ações } \\
\text { coletivas/total de PMEs } \\
\text { do Projeto APL }\end{array}$ & $\%$ & semestral & \\
\hline
\end{tabular}


desempenho eficiência coletiva, foi selecionado o indicador relacionado com a ação coletiva operacionalizada no cluster: compra coletiva de fibra. $\mathrm{O}$ resultado deste indicador demonstra o ganho econômico que as empresas adquirem quando participam de uma ação cooperada. A cooperação empresarial das empresas também foi avaliada a partir do indicador que representava em termos de porcentagem as empresas envolvidas nas ações de cooperação. É um resultado que retrata a disponibilidade das empresas e do nível de capital social que existe no cluster para executar projetos de cooperação.

Para reunir os dados das empresas do APL Ibitinga, foi construída uma planilha eletrônica com 6 variáveis: Consumo Intermediário de Produção, Receita Bruta Mensal, Total de Impostos, Total de Despesas Financeiras, Número de Pessoas Ocupadas e Número Total de Peças Produzidas. As informações foram retiradas dos sistemas ou relatórios financeiros das empresas e foram utilizados para avaliar as dimensões de desempenho das empresas e resultados econômicos/sociais do cluster. Outros dados como, pessoas qualificadas, quantidade de matéria-prima comprada coletivamente e número total de PMEs que participam dos projetos de cooperação, foram solicitados do agente local (SINDICOBI), responsável pelo projeto de cooperação das empresas e pela definição da agenda dos cursos de capacitação dos recursos humanos locais.

O ciclo de medição de desempenho foi construído tomando como base cinco períodos. O primeiro é o $\mathrm{T}^{0}=$ abril de 2004 até março de 2005 , período que representa a situação das empresas antes de iniciar o projeto de cooperação e é utilizado como base de comparação. As outras avaliações são relacionadas com os períodos $T^{1}=$ abril de 2005 até setembro de 2005; $\mathrm{T}^{2}=$ outubro de 05 até março de 2006; $\mathrm{T}^{3}=$ abril de 2006 até setembro de 2006; e $\mathrm{T}^{\mathrm{FINAL}}=$ outubro de 2006 até fevereiro de 2007, intervalos associados com o início e a conclusão do processo de implantação de todas as atividades do projeto de cooperação. Com o objetivo de estabelecer a base de desempenho do arranjo produtivo $\left(\mathrm{T}^{0}\right)$ e iniciar o processo de avaliação $\left(\mathrm{T}^{1}\right)$, os pesquisadores coletaram os dados de 26 empresas de dezembro de 2005 até fevereiro de 06. Nesta atividade, também participou a equipe de coordenação do projeto do convênio SEBRAE/FIESP/SINDICOBI. Foi possível perceber que a prática de mensuração de desempenho coletivo e individual era desconhecida para a maioria dos empresários, existiam falhas (fórmula, denominação e software) nas informações utilizadas no processo de gestão empresarial, criando com isso distorções nos custos fixos e variáveis, e/ou despesas das empresas.

Os resultados dos primeiros dois períodos avaliados foram apresentados para os empresários e coordenadores do projeto, em março de 2006. Os pesquisadores reforçaram as vantagens competitivas que podem ser alcançadas quando os processos de negócio são monitorados e contro- lados, e destacaram a necessidade de revisar o modelo de coleta de informações. Nesta etapa, foram introduzidos novos indicadores de desempenho: Lucratividade das PMEs e Porcentagem de empresas envolvidas nas ações de cooperação - Quadro 1. Além disso, a planilha de coleta de dados foi revisada e implantada por um dos pesquisadores do projeto nas empresas interessadas.

Em outubro de 2006, foram coletados os dados para os períodos $\mathrm{T}^{2}$ e $\mathrm{T}^{3}$. Nesta nova fase de coleta de dados, o número de participantes do projeto reduziu para 12 empresas. Isto obrigou os pesquisadores a retirar os dados de 14 empresas que participaram dos primeiros períodos de avaliação do desempenho. O principal motivo da desistência é a dificuldade para fornecer a informação das variáveis. A última avaliação de desempenho ( $\mathrm{T}^{\mathrm{FINAL}}$ ) foi realizada em março de 2007. Data na qual terminou o primeiro ciclo do processo de medição de desempenho do APL Ibitinga. Os resultados e a meta específica para cada um dos indicadores de desempenho são descritos no painel de gestão visual do APL Ibitinga - Figura 5.

Para gerenciar a perspectiva de desempenho relacionada à empresas, são utilizados quatro indicadores de desempenho: produtividade das PMEs, preço médio de vendas dos produtos, custo total das PMEs Negócio e lucratividade das empresas negócio. Analisando-se todos os indicadores de uma forma integrada, é possível afirmar que as empresas conseguiram agregar valor aos produtos fabricados e, com isso, aumentaram a produtividade dos processos e o preço médio de venda dos produtos comercializados. Consequentemente, esse crescimento implica o aumento dos custos totais das empresas e a contratação de mão-de-obra qualificada.

É possível afirmar também que as metas estabelecidas para o projeto foram superiores à capacidade de resposta das empresas ao processo de melhoria e mudança implantado no arranjo produtivo. Entretanto, os resultados demonstram que as empresas aumentaram o desempenho individual e, consequentemente, o coletivo do arranjo produtivo. As variações registradas pelos indicadores de Produtividade das PMEs, custo total das PMEs negócio e pessoas Ocupadas podem ser atribuídas ao próprio processo de aprendizagem da prática de medição de desempenho e, principalmente, à sazonalidade da demanda do mercado. Neste caso, percebe-se que o valor reduz drasticamente no período de baixa sazonalidade (out.-mar.) e é equilibrado pelas empresas no período de alta produtividade (abr.-set.), isto também é observado por meio do indicador de lucratividade das empresas negócio. Para reverter essa situação no APL Ibitinga, ações de melhoria foram planejadas para os períodos que antecedem a essa redução de produtividade das empresas: feira de negócios, antecipação do lançamento do catálogo de produtos e prospecção de novos mercados. 

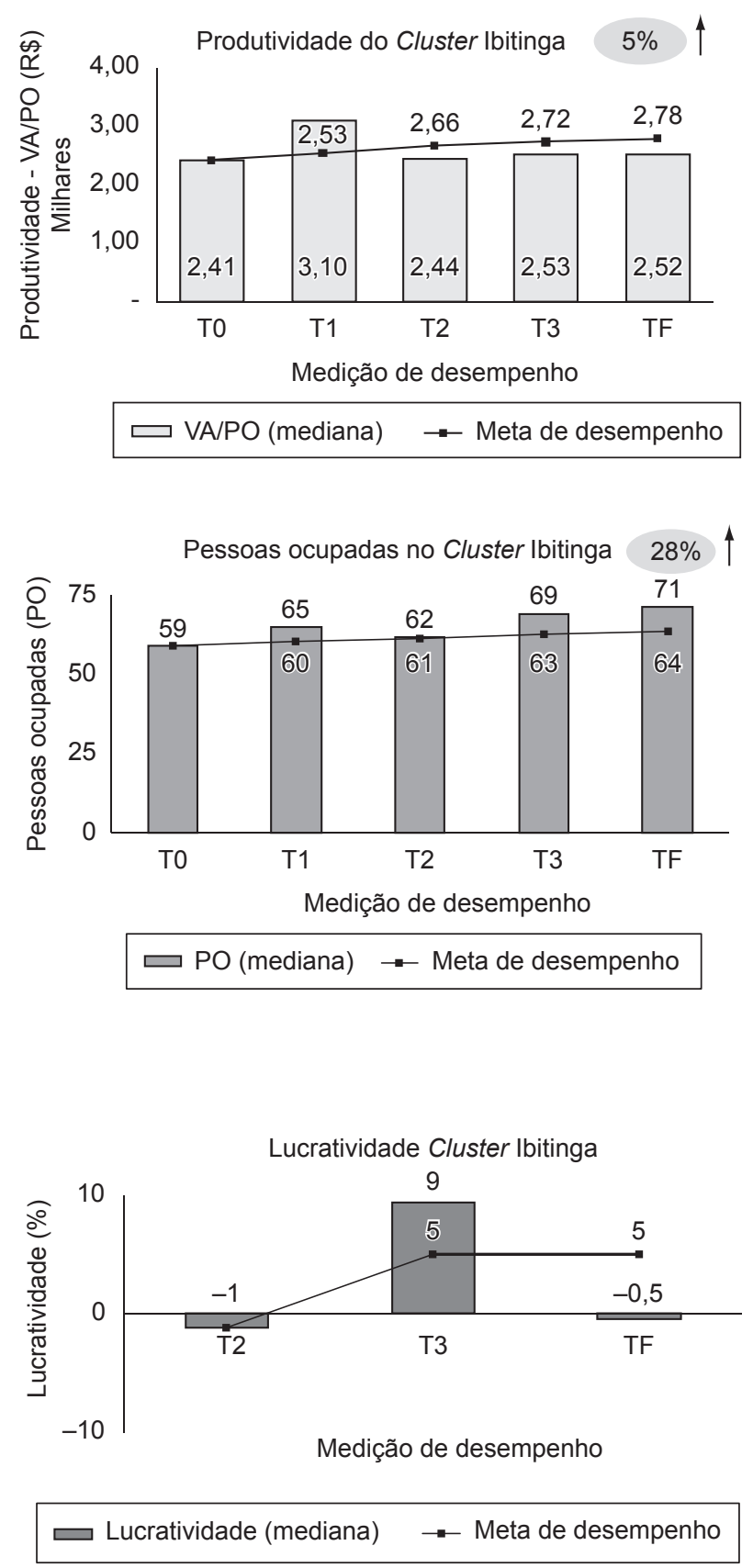
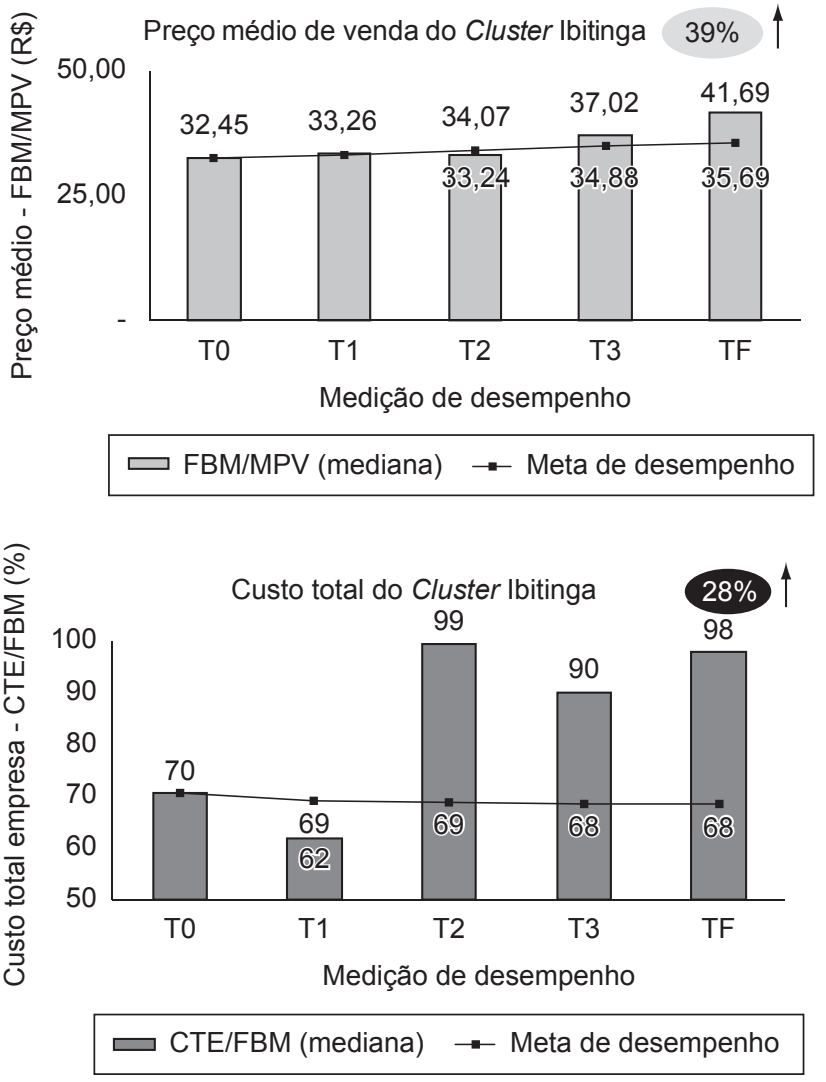

Capacitação de recursos humanos - Cluster Ibitinga Out-2006

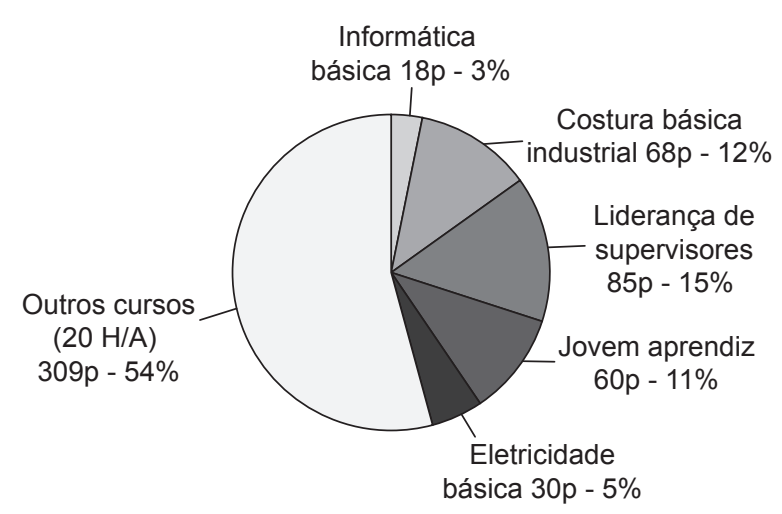

\begin{tabular}{|l|c|c|c|c|}
\hline \multicolumn{1}{|c|}{ Perspectiva } & Indicador do APL Ibitinga & Período & Resultado & Frequência de participação \\
\hline Econômica/social & Pessoas qualificadas & Outubro de 2006 & 567 pessoas & - \\
\hline Eficiência coletiva & $\begin{array}{c}\text { Compra coletiva fibra } \\
\text { (ganho de 23\% no processamento de fibra) }\end{array}$ & $\begin{array}{c}\text { Dezembro de } 2006 \text { até } \\
\text { abril de } 2006\end{array}$ & $33 \%$ & 5 PMEs/Mês \\
\hline $\begin{array}{c}\text { Capital social } \\
\text { Porcentagem de empresas envolvidas nas } \\
\text { ações de cooperação }\end{array}$ & $\begin{array}{c}\text { Novembro de 2005 até } \\
\text { novembro de 2006 }\end{array}$ & $33 \%$ & 12 PMEs \\
\hline
\end{tabular}

Figura 5. Painel de gestão visual do SMD do APL Ibitinga. 
Os resultados econômicos e sociais alcançados a partir de um projeto de desenvolvimento sistemático são representados pelos indicadores de desempenho: capacitação de recursos humanos locais e número total de pessoas ocupadas. Nos dois casos, percebe-se que há um crescimento do número de pessoas contratadas e capacitadas na atividade econômica do local. A capacitação e treinamento promovem também o desenvolvimento humano e do conhecimento cognitivo das atividades desenvolvidas nas empresas, melhorando com isso a qualidade dos produtos e dos processos industriais. Isto reforça o poder de negociação das empresas e aumenta o valor agregado. A variação negativa $\left(\mathrm{T}^{2}\right)$ percebida no indicador de pessoas ocupadas decorre do próprio comportamento sazonal da demanda do mercado.

Para a perspectiva de desempenho capital social, é considerada a porcentagem de empresas envolvidas nas ações de cooperação. A meta era motivar pelo menos $50 \%$ das empresas a participar dos projetos de cooperação. Os resultados $(33 \%)$ demonstram que há uma disposição dos empresários para cooperar nos projetos que promovem benefícios coletivos. É um indicador que permite acompanhar o comportamento dos empresários, agentes locais e instituições, identificar os atores de governança do grupo e definir as ações de cooperação mais críticas dos participantes.

A eficiência coletiva do APL Ibitinga é avaliada a partir dos resultados que as empresas alcançam a partir de uma ação cooperada. Neste caso, pelos resultados que as empresas alcançaram coletivamente, a ação mais significativa foi a compra coletiva. $\mathrm{O}$ objetivo foi reduzir os custos logísticos decorrentes do transporte da fibra e do processamento da manta acrílica, utilizada na fabricação dos produtos de decoração para enxovais de cama. $\mathrm{O}$ indicador desempenho demonstra que em média $33 \%$ (9/30 ton/mês) da capacidade total de entrega da manta disponibilizada pelo fornecedor foram utilizados pelas empresas do APL Ibitinga. O projeto exigia a elaboração de um termo de cooperação entre as empresas e o fornecedor, o planejamento antecipado do consumo de matéria-prima das PMEs, a definição de um agente responsável pela coordenação e uma conscientização dos empresários sobre a distribuição bilateral (fornecedorcliente) dos benefícios adquiridos, elementos que podem assegurar a manutenção dessa ação cooperada. Com o intuito de evitar alguns conflitos entre os empresários e isso prejudicar outros projetos de cooperação, essa ação foi cancelada até definir-se claramente o processo de planejamento e execução da compra coletiva.

Os resultados alcançados com o projeto de cooperação da SEBRAE/FIESP/SINDICOBI reforçam a necessidade de continuar com a implantação de novas ações de melhoria nas áreas de produção, recursos humanos, planejamento estratégico e financeiro, e cursos de capacitação nas áreas de produção, design industrial, manutenção de equipamentos, gestão de estoques etc. (GALDAMEZ, 2007). Na etapa de conclusão do projeto científico, os pesquisadores desenvolveram e apresentaram um novo plano de ações de melhoria para o APL Ibitinga. No modelo, foram consideradas as ações de melhoria relacionadas às perspectivas de gestão definidas como áreas críticas de desempenho: Gestão estratégica do APL, Desempenho das Empresas, Eficiência Coletiva, Econômica Local e Capital Social. Também neste plano, é definido o objetivo, o público alvo, a meta e o responsável pelo planejamento e execução. A proposta foi considerada para elaborar um novo projeto de cooperação do APL Ibitinga. Esse novo projeto foi avaliado e aprovado pelo SEBRAE-SP, em 2008, e se encontra na fase de implantação.

\subsection{Arranjo produtivo local de Jaú - indústria do calçado feminino}

O APL (arranjo produtivo local) de calçados femininos compreende as cidades de Jaú, Barra Bonita, Dois Córregos, Mineiros do Tietê, Bocaina e Bariri. É uma atividade industrial que corresponde à fabricação de calçados de couro, código CNAE 19.31-3 (IBGE, 2003). Dados do Sindicato de Calçados de Jaú (SINDICALÇADOS) indicam que no arranjo produtivo existem, aproximadamente, 250 PMEs. Conforme a instituição, tais empresas produzem em média 100 mil pares de sapatos por dia, atendem 95\% da demanda de sapatos femininos no Brasil, e a concentração da indústria gera cerca de 8000 (oito mil) postos de trabalho diretos na região.

A concentração de PMEs promove as seguintes vantagens competitivas: concentração de fornecedores de componentes, máquinas e ferramentas; formação contínua de mão-de-obra (SENAI, FATEC, instituições de ensino superior) e melhoria da infraestrutura de comercialização dos produtos e instituições locais.

O SEBRAE-SP e o SINDICALÇADOS, desde abril de 2005, desenvolvem e coordenam um projeto de cooperação com 50 PMEs no APL Jaú e a metodologia de intervenção é similar ao projeto desenvolvido no APL Ibitinga (ver Figura 4). O objetivo deste projeto é aumentar o volume de pares comercializados, o preço médio de vendas dos pares de calçados e a produtividade das PMEs. As ações de melhoria implantadas no arranjo produtivo são: qualificação de mão-de-obra (gerentes e operadores); consultoria empresarial nas áreas de desenvolvimento de produtos, vendas, produção e finanças; o projeto coletivo de coleta do resíduo industrial; projeto de cesta básica; projeto de missões empresariais e participação de feiras; projeto de cooperação da saúde do trabalhador da indústria de calçados; projeto do portal de benchmarking; e projeto de Jaú recicla. Neste projeto formal de cooperação, diferentes instituições participam como parceiras nas iniciativas: UFSCar, USP/EESC, FIJ, FATEC, SENAI, Prefeitura Municipal de Jaú, UNIMED, ASSINTECAL, APEX e a FINEP. 
Neste APL, também existia a necessidade de avaliar o desempenho e coordenar as iniciativas do processo de inovação contínua. $\mathrm{O}$ ambiente também apresentava características positivas de cooperação e confiança entre os empresários e instituições locais que poderiam facilitar o desenvolvimento da proposta.

\subsubsection{Processo de medição e avaliação de desempenho no arranjo produtivo local de Jaú}

Em agosto de 2006, foram programadas reuniões para construir os objetivos do SMD com os coordenadores do projeto APL (arranjo produtivo local) Jaú (SEBRAE-SP), gestores do SINDICALÇADOS, representantes das empresas e coordenadores de instituições localizadas no município (SENAI e FATEC). A partir das reuniões, foram definidos alguns requisitos para o projeto de medição de desempenho:

a) a proposta de medição de desempenho para Jaú utilizaria uma perspectiva de desempenho ambiental.
Essa perspectiva deve avaliar a quantidade total do resíduo coletado nas empresas. A partir dos resultados, algumas ações de melhoria poderiam ser discutidas no cluster de Jaú;

b) o SMD deveria focar a avaliação das atividades relacionadas com a produtividade, as áreas financeiras, os recursos humanos, a cooperação e os impactos ambientais. Dimensões definidas a partir das observações dos stakeholders do cluster, pois investimentos vinham sendo realizados para promover o desempenho das empresas nessas áreas;

c) a infraestrutura necessária para operacionalizar a proposta seria disponibilizada pelo agente de governança local: SINDICALÇADOS, pois é um ator que exerce bastante influência nas decisões do cluster, decorrente do próprio processo de governança desenvolvido durante os últimos anos. Ainda, um Portal de benchmarking seria utilizado para compilar as informações de desempenho do cluster (OIKO, 2007).

Quadro 2. Indicadores de desempenho do APL Jaú.

\begin{tabular}{|c|c|c|c|c|c|c|c|}
\hline $\begin{array}{c}\text { Perspectiva } \\
\text { de } \\
\text { desempenho }\end{array}$ & $\begin{array}{c}\text { Indicadores } \\
\text { de } \\
\text { desempenho }\end{array}$ & Objetivo & Meta & $\begin{array}{l}\text { Método } \\
\text { de } \\
\text { cálculo }\end{array}$ & Unidade & $\begin{array}{c}\text { Frequência } \\
\text { da } \\
\text { medida }\end{array}$ & Resp. \\
\hline \multirow[t]{3}{*}{$\begin{array}{l}\text { Desempenho } \\
\text { das empresas }\end{array}$} & $\begin{array}{l}\text { Preço médio } \\
\text { do calçado por } \\
\text { coleção }\end{array}$ & $\begin{array}{l}\text { Aumentar o } \\
\text { valor do } \\
\text { mercado }\end{array}$ & $10 \%$ & $\begin{array}{l}\text { Faturamento bruto } \\
\text { no período } T^{\mathrm{n}} / \\
\text { pares produzidos } \\
\text { no período } \mathrm{T}^{\mathrm{n}}\end{array}$ & $\begin{array}{l}\mathrm{R} \$ / \text { Pares de } \\
\text { sapato }\end{array}$ & mensal & \\
\hline & $\begin{array}{l}\text { Produtividade do } \\
\text { funcionário por } \\
\text { coleção }\end{array}$ & $\begin{array}{l}\text { Melhorar a } \\
\text { produtividade }\end{array}$ & $15 \%$ & $\begin{array}{l}\text { Pares produzidos } \\
\text { no período } \mathrm{T}^{\mathrm{n}} / \\
\text { pessoas ocupadas } \\
\text { no período } \mathrm{T}^{\mathrm{n}}\end{array}$ & $\begin{array}{l}\text { Pares de } \\
\text { sapatos/PO }\end{array}$ & mensal & \\
\hline & $\begin{array}{l}\text { Pares de calçados } \\
\text { produzidos e } \\
\text { comercializados } \\
\text { por coleção }\end{array}$ & $\begin{array}{l}\text { Promover o } \\
\text { crescimento } \\
\text { das PMEs }\end{array}$ & $15 \%$ & $\begin{array}{l}\text { Pares produzidos e } \\
\text { comercializados } \\
\text { no período } \mathrm{T}^{\mathrm{n}}\end{array}$ & $\begin{array}{l}\text { Pares de } \\
\text { sapatos }\end{array}$ & mensal & 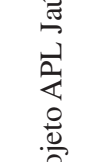 \\
\hline \multirow[t]{2}{*}{$\begin{array}{l}\text { Resultados } \\
\text { econômicos e } \\
\text { sociais }\end{array}$} & Pessoas ocupadas & $\begin{array}{l}\text { Incentivar a } \\
\text { contratação de } \\
\text { pessoas no APL Jaú }\end{array}$ & $5 \%$ & $\begin{array}{l}\text { Pessoas ocupadas nas } \\
\text { empresas do projeto } \\
\text { APL Jaú }\end{array}$ & Pessoas & mensal & $\begin{array}{l}\frac{.}{2} \\
0 \\
0 \\
.00 \\
\tilde{J}\end{array}$ \\
\hline & $\begin{array}{l}\text { Pessoas } \\
\text { qualificadas }\end{array}$ & $\begin{array}{l}\text { Melhorar a } \\
\text { habilidade e } \\
\text { capacitar a } \\
\text { mão-de-obra local }\end{array}$ & 300 & $\begin{array}{l}\text { Pessoas treinadas no } \\
\text { projeto APL Jaú }\end{array}$ & Pessoas & mensal & 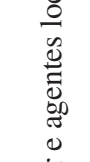 \\
\hline $\begin{array}{l}\text { Eficiência } \\
\text { coletiva }\end{array}$ & $\begin{array}{l}\text { Compra coletiva } \\
\text { de cestas básicas }\end{array}$ & $\begin{array}{l}\text { Reduzir os custos do } \\
\text { processo de compra } \\
\text { de cestas básicas }\end{array}$ & $10 \%$ & $\begin{array}{l}\text { Custo total da } \\
\text { compra de cestas } \\
\text { básicas/número } \\
\text { de cestas básicas }\end{array}$ & $\begin{array}{l}\mathrm{R} \$ / \text { cestas } \\
\text { básicas }\end{array}$ & mensal & 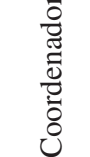 \\
\hline Capital social & $\begin{array}{l}\text { Empresas } \\
\text { envolvidas nas } \\
\text { ações de } \\
\text { cooperação }\end{array}$ & $\begin{array}{l}\text { Aumentar o número } \\
\text { de participantes }\end{array}$ & $75 \%$ & $\begin{array}{l}\text { Total de PMEs que } \\
\text { participam de ações } \\
\text { coletivas/total de PMEs } \\
\text { do projeto APL Jaú }\end{array}$ & $\%$ & mensal & \\
\hline Meio ambiente & $\begin{array}{l}\text { Coleta do resíduo } \\
\text { industrial }\end{array}$ & $\begin{array}{l}\text { Aumentar a } \\
\text { quantidade de } \\
\text { resíduo coletado } \\
\text { no APL Jaú }\end{array}$ & 250 & $\begin{array}{l}\text { Quantidade de resíduo } \\
\text { industrial coletado }\end{array}$ & tonelada & mensal & \\
\hline
\end{tabular}


No processo de desenvolvimento do SMD do arranjo produtivo de Jaú, 8 (oito) encontros foram realizados no período de agos./06 até nov./06, para definir as metas, as perspectivas de gestão de desempenho dos APLs, os respectivos IDs e o responsável para coletar e analisar as informações. $\mathrm{O}$ Quadro 2 apresenta os IDs associados ao processo de gestão de desempenho do APL Jaú. Nesta etapa, os indicadores de desempenho foram selecionados em função das necessidades dos atores de governança local: gerenciar o processo de inovação contínua do APL, carência de informações sobre o desempenho das PMEs, necessidade de identificar as lacunas de desempenho, justificar novos projetos ou programas de desenvolvimento, incentivar a cooperação e divulgar os resultados no meio empresarial com o objetivo de fortalecer a governança local.

Oiko (2007) desenvolveu um projeto-piloto e utilizou três indicadores para avaliar a perspectiva de desempenho das empresas: Preço médio do calçado por coleção; Produtividade do funcionário por coleção; Pares de calçados produzidos e comercializados por coleção. Nesta iniciativa participaram treze (13) empresas que já estavam integradas com as ações de melhoria desenvolvidas por meio do Projeto APL Jaú. Tais empresas recebiam serviços de consultoria nas áreas de administração geral e finanças, produção e marketing. O processo de implantação foi conduzido pela pesquisadora e contou com a colaboração de uma funcionária do SINDICALÇADOS. Uma das principais observações desse trabalho é que as PMEs apresentaram infraestruturas organizacionais díspares e apenas um pequeno número destas possuíam um modelo de gestão empresarial. Tais diferenças limitaram o uso da medição de desempenho do aglomerado e desmotivaram a participação das PME's no projeto de medição de desempenho do APL Jaú.

Para os indicadores de desempenho: Pessoas Qualificadas, Pessoas Ocupadas, Compra coletiva de cesta básica, Porcentagem de empresas cooperando e Coleta do resíduo industrial, uma planilhaeletrônicaseriaencaminhadamensalmente aos coordenadores dos próprios projetos: SENAI, SEBRAE, SINDICALÇADOS e FATEC. Entretanto, está atividade não foi acompanhada pelos pesquisadores.

Para integrar o projeto de gestão de desempenho e a prática de medição de desempenho, apresentou-se a proposta de desenvolvimento de ações de melhoria para o APL Jaú. Nesta fase do projeto, procurou-se identificar as ações necessárias para a orientação estratégica dos APLs, as práticas de melhoria que podem promover o desempenho industrial das PMEs, os projetos de cooperação que alavancariam o desempenho coletivo, as atividades de treinamento que incentivariam a qualificação da mão-de-obra local e os projetos coletivos que reduziriam os impactos ambientais. É uma atividade que ajudou a reposicionar as ações que são desenvolvidas a partir do projeto formal de cooperação dentro de uma visão de modelo de gestão de desempenho (GALDAMEZ, 2007).

\subsection{Análise da pesquisa de campo}

A proposta de avaliação de desempenho para APLs é construída a partir da interação com os gestores e agentes de governança dos APLs de Ibitinga e Jaú. Isto tornou a proposta mais próxima das reais necessidades do processo de gestão de desempenho dos arranjos produtivos pesquisados. A seguir, são destacados os pontos analisados durante o desenvolvimento do trabalho de campo.

No APL Ibitinga, se observou que a avaliação de desempenho fortaleceu o processo gestão de desempenho coordenado pelos atores locais ou agentes de governança. Os resultados foram utilizados para revisar o plano de ações e incorporar novas atividades para promover a inovação contínua. A medição de desempenho também fortaleceu o processo de governança local. Os resultados foram divulgados em diversos meios de comunicação e isso promoveu a marca do APL. O APL Ibitinga passou a ser considerado um caso de sucesso dentro dos programas de cooperação promovidos no Brasil e outras instituições governamentais passaram a disponibilizar recursos financeiros.

O ciclo de medição de desempenho do APL Ibitinga também benefíciou às empresas. Os empresários/gerentes passaram a preocupar-se mais com o controle dos custos fixos e variáveis do sistema de gestão empresarial, os estoques de matéria-prima, os desperdícios do processo produtivo e o processo de comercialização dos produtos com maior valor agregado. Além disso, essa atitude refletiu na qualidade da informação coletada. Os empresários demonstraram mais confiança e cooperação nas informações fornecidas, assegurando com isso um processo de tomada de decisão mais adequado no APL Ibitinga. Isto também motivou os empresários para participar do processo de gestão de desempenho do próprio APL. Nos encontros para apresentar os resultados, algumas ações de cooperação foram discutidas entre os participantes, estimulando com isso a formação de um ambiente de confiança entre os empresários e agentes locais.

No decorrer da pesquisa de campo, se observou que existia uma dificuldade para coletar as variáveis do SMD do APL Ibitinga. Entre as empresas, existiam diferentes modelos de gestão empresarial e problemas estruturais nos sistemas de informação. Aspectos que limitam o desenvolvimento de um sistema coletivo de avaliação do desempenho para o APL. As principais dificuldades são relacionadas com a falta de informação, diferentes métodos de cálculo das variáveis dos sistemas financeiros, falta de comunicação entre as bases de dados, softwares desenvolvidos em linguagem de difícil atualização e revisão das funções, dificuldade para disponibilizar recursos humanos nas atividades relacionadas com a gestão de informações e conflitos entre os programadores locais e empresários. Tais barreiras motivaram a saída das empresas do projeto de pesquisa.

Um dos pesquisadores implantou a planilha excell em nove empresas para facilitar o processo de coleta de dados 
no APL Ibitinga. Isto trouxe vários aspectos positivos: os empresários passaram a utilizar tais informações no planejamento estratégico e processo de tomada de decisão, solicitar a visita do pesquisador para colaborar com a análise de desempenho da empresa e revisar o sistema de informação.

Outro fator que prejudicou a avaliação de desempenho do APL Ibitinga foi a limitação da infraestrutura de cooperação. Existia uma baixa disponibilidade de recursos humanos e financeiros para coletar as informações das empresas e isso terminava prolongando o período de avaliação de resultados. Isto ocorreu porque outros projetos de cooperação empresarial também estavam sendo executados paralelamente e demandavam o uso dos recursos. As informações utilizadas para avaliar as dimensões de desempenho econômica/social, eficiência coletiva e capital social também foram difíceis de coletar, pois, nos agentes de governança, não existiam mecanismos de gestão e controle de resultados dos projetos de cooperação desenvolvidos no APL. Com o objetivo de facilitar a avaliação de desempenho, os pesquisadores desenvolveram ferramentas de controle dos projetos como, por exemplo, planilhas para reunir informações sobre o número de matriculados e concluintes dos cursos de capacitação, quantidade de horas de treinamento, quantidade de matéria-prima solicitada por meio da ação coletiva etc.

No APL Jaú, existia um ambiente propício para desenvolver o projeto avaliação de desempenho. Os pesquisadores destacaram que para implantar e usar a proposta era necessário realizar esforços coletivos nos seguintes aspectos: elaboração do planejamento estratégico, definição de uma equipe de medição de desempenho, padronização de informações e estabelecimento de um ambiente de cooperação empresarial e confiança entre os empresários e agências que promovessem o desempenho do cluster. A pesquisa focou o desenvolvimento do projeto do SMD para o APL Jaú e a implantação da proposta de avaliação de desempenho foi conduzida por Oiko (2007). As principais dificuldades observadas são: as empresas demoravam a fornecer os dados das variáveis no portal de bechmarking, outras agências coletavam as mesmas informações e isso criava um sentimento de repetição nas operações e uma falta de clareza na disposição dos dados na ferramenta desenvolvida pelo grupo de pesquisa (OIKO, 2007). As outras dimensões de desempenho não foram avaliadas pelos pesquisadores. Também foi observado que a medição de desempenho, apesar dessas dificuldades, subsidiou os agentes de governança com informações relacionadas ao desempenho das PMEs. Deve-se destacar que as instituições demonstraram interesses por esses dados para monitorar suas ações e tomar decisões sobre o processo de gestão de desempenho do aglomerado. Além disso, em princípio, com a implantação da proposta, não foram percebidas mudanças nos aspectos relacionados com a confiança e cooperação do APL Jaú.

\section{Considerações finais}

A medição de desempenho tornou as informações do cluster e das empresas mais seguras e confiáveis para serem usadas no processo de tomada de decisão. Outra contribuição da proposta está relacionada com a operacionalização dos projetos coordenados pelas instituições governamentaise particularesqueparticiparam dapesquisa de campo. O processo de implantação dos programas de desenvolvimento está articulado com os investimentos planejados para a melhoria da infraestrutura, a integração territorial, o fortalecimento das competências, vocações e oportunidades tecnológicas (produtos e processos) das PMEs. Nesse sentido, o SMD ajudou a direcionar os recursos financeiros disponíveis dessas iniciativas para as áreas críticas ou lacunas de desempenho identificadas nas PMEs e dos próprios APLs.

Para implantar a proposta é necessário desenvolver um trabalho extenso e de longo prazo com os agentes locais e PMEs do APL. Para tal, torna-se imprescindível disponibilizar uma quantidade de recursos financeiros e uma infraestrutura adequada (pessoas qualificadas, instalações físicas no local e disponibilidade de recursos materiais) para desenvolver o projeto nas empresas. $\mathrm{O}$ processo utilizado pelos pesquisadores para introduzir a prática de medição de desempenho é genérico e não foi possível avaliá-lo adequadamente durante o desenvolvimento do trabalho. As etapas foram sendo construídas e analisadas conforme as necessidades observadas pelos pesquisadores durante a implantação da proposta. Atividades que foram conduzidas e validadas a partir do método científico utilizado durante a pesquisa de campo: pesquisa-ação.

Nota-se que nos arranjos produtivos outros fatores que também influenciam o processo de gestão de desempenho são: visões diferentes das instituições governamentais e locais sobre o conceito de medição de desempenho, os recursos humanos limitados (funcionários ocupam várias funções na empresa), as deficiências da infraestrutura da empresa, os aspectos culturais das PMEs (relacionados ao ambiente social e econômico) e a existência de problemas gerenciais (os gerentes desconhecem os métodos e as ferramentas de qualidade).

A prática de medição de desempenho inicia o processo de construção de uma rede de cooperação de PMEs mais integrada nos arranjos produtivos, pois identifica as lacunas de desempenho do APL, direciona o processo de tomada de decisão e suporta o desenvolvimento sistemático de ações de melhoria e mudança empresarial. Tais informações podem direcionar os investimentos e a formatação das políticas de desenvolvimento econômico, industrial e social apresentadas pelas instituições governamentais, universidades e centro de pesquisa, setores privados, agentes locais e as próprias empresas do arranjo 
produtivo. Ainda, a prática contribuiu para fortalecer a marca do cluster. A divulgação das informações sobre o desempenho do cluster pode motivar outras agências governamentais e estaduais a investir nas PMEs por meio de projetos de cooperação empresarial.

A medição de desempenho é um mecanismo que promove a cooperação empresarial entre as PMEs do APL, incentiva a prática do benchmarking nos encontros promovidos para apresentar os resultados e desenvolver um plano integrado de ações de melhoria com as perspectivas de desempenho. Além disso, foi possível integrar os objetivos do APL com as atividades gerenciais e operacionais das PMEs. A prática de medição de desempenho no APL também motivou os empresários a utilizar indicadores de desempenho no processo de gestão da empresa.

O trabalho demonstra que a medição de desempenho do cluster pode ser influenciada por algumas situações inerentes ao próprio ambiente industrial: infraestrutura de gestão empresarial, nível de confiança e cooperação, infraestrutura disponível para implantar a prática e diferentes interesses dos stakeholders.
Uma questão crítica na medição de desempenho do aglomerado é a dependência do sistema de medição de desempenho das PMEs. É uma barreira que impossibilita a avaliação do desempenho do APL. Neste sentido, é necessário desenvolver novas pesquisas para: $i$ ) identificar mecanismos mais simples de reunir as informações do sistema de medição de desempenho do aglomerado; ii) desenvolver um processo para introduzir a prática de avaliação de desempenho nas PMEs do APL; e iii) projetar o SMD da própria empresa integrado com as perspectivas de desempenho proposta neste trabalho.

Existem também dificuldades associadas com o método científico utilizado para conduzir a pesquisa de campo nos APLs. A pesquisa-ação é um procedimento de construção da teoria, que influencia diretamente a definição dos objetivos da pesquisa, atitude que leva a revisar constantemente as questões de pesquisa e constantemente a alterar e revisar as atividades científicas, consequentemente, isto altera o cronograma de atividades e, na maioria das vezes, demanda o uso de novos recursos econômicos e financeiros.

\title{
Purpose of a performance measurement system for an industrial cluster
}

\begin{abstract}
Industrial clusters or cooperation network is an interesting alternative in promoting the sustainable development of Small and Medium Enterprises (SME's). The fundamental characteristics for managing the performance of clusters are the identification of the stakeholders, definitions of common strategies and objectives, development of collaborative improvement actions, design of a performance management system, organization of a support infrastructure, and promotion of social capital. The concepts of a performance management system can be of great value in managing collective efficiency and performance improvement of the companies of the cluster. The purpose of this article is to describe a model for the performance measurement and management of a cluster. In order to develop this study, a field research was carried out in two industrial clusters: Ibitinga, a textile industry cluster and Jau, a Lady's footwear cluster. The results show the applicability of performance measurement systems for the performance management of a cluster. It also helps to integrate the objectives of performance establishing actions, evaluating results promoting cooperation to improve the collective efficiency of a cluster.
\end{abstract}

Keywords: Industrial cluster. Performance measurement system. Continuous improvement. Small and medium enterprise.

\section{Referências Bibliográficas}

ÁLVARO, J. A. H. Sistema de indicadores para la mejora y el control integrado de la calidad de los procesos. Castelló de la Plana: Publicacions de la Universitat Jauma, 2001. 219 p.

AMATO NETO, J. (Org.). Redes entre organizações: domínio do conhecimento e da eficácia operacional. São Paulo: Atlas, 2005.

BITITCI, U. S.; CARRIE, A. S.; McDEVITT, L. Integrated performance measurement systems: a development guide. International Journal Operations \& Production Management, v. 17, n. 5 , p. $522-534,1997$.

BOURNE, M. Researching performance measurement system implementation: the dynamics os success and failure. In: ENCONTRO NACIONAL DE ENGENHARIA DE
PRODUÇÃO, 22/ITERNATIONAL CONFERENCE ON INDUSTRIAL MANAGEMENT, 8, 2002, Curitiba. Anais eletrônico... Curitiba: PUCPR, 2002. (CD-ROM).

CARPINETTI, L. C. R. Uma proposta para o processamento de identificação e desdobramento de melhorias da manufatura: uma abordagem estratégica. São Carlos, 2000. 170p. Tese (Livre-Docência) - Escola de Engenharia de São Carlos, Universidade de São Paulo.

CARPINETTI,L.C.R.; MARTINS, R.A. Continuous improvement strategies and production competitive criteria: some findings in brazilian industries. Total Quality Management, v. 12, n. 3, p. 281-291, 2001. 
CASSIOLATO, J. E.; LASTRES, H. M. M. O foco em arranjos produtivos e inovativos locais de micro e pequenas empresas. In: LASTRES, H. M. M.; CASSIOLATO, J. E.; MACIEL, M. L. (Org.). Pequena empresa: cooperação e desenvolvimento local. Rio de Janeiro: Relume Dumará; UFRJ/Instituto de Economia, 2003. Cap. 1, p. 21-34.

CROSS, K. F.; LYNCH, R. L. Managing the corporate warriors. Quality Progress, v. 23, n. 4, p. 54-59, 1990

COUGHLAN, P.; COGHLAN, D. Action research for operations management. International Journal of Operations \& Production Management, v. 22, n. 2, p. 220-240, 2002.

DIXON, J. R.; NANNI Jr., J. A.; VOLLMANN, T. E. The new performance challange: measuring operations for world-class competition. New York: Business One Irwin, 1990. Cap. 4, p. 66-91.

EISENHARDT, K. M. Building theories from case study research. Academy of Management Review, v. 14, n. 4, p. 532-550, Oct. 1989.

ENRIGHT, M. J. Regional cluster and firm strategy. In: The dynamic firm: the role of regions, technology, strategy and organization. Sweden: [s.n.], 1994. p. 1-30.

GALDAMEZ, E. V. C. Proposta de um Sistema de Medição de Desempenho para Clusters Industriais de Pequenas e Médias Empresas. São Carlos, 2007. 194 p. Tese (Doutorado) - Escola de Engenharia de São Carlos, Universidade de São Paulo.

GARENGO, P.; BIAZZO, S.; BITITCI, U. S. Performance measurement systems in SMEs: a review for a research agenda. International journal of management reviews, v. 7 , n. 1 , p. 25-47, 2005.

GEROLAMO, M. C. Proposta de sistematização para o processo de gestão de melhorias e mudanças de desempenho. São Carlos, 2003. 151p. Dissertação (Mestrado) - Escola de Engenharia de São Carlos, Universidade de São Paulo.

GEROLAMO, M. C.; CARPINETTI, L. C. R.; CARDOZA, E. Gestão de melhoria e mudança em redes de cooperação de PME's: uma abordagem conceitual. In: ENCONTRO NACIONAL DE ENGENHARIA DE PRODUÇÃO, 25, 2005. Anais... Porto Alegre: ABEPRO, 2005. (CD-ROM).

GEROLAMO, M. C.; CARPINETTI, L. C. R.; SELIGER, G.; GALDAMEZ, E. V. C. Performance management of regional clusters and SME cooperation networks. International Journal of Business Excellence, v. 1, n. 4, p. 457-483, 2008.

GIL, A. C. Métodos e técnicas de pesquisa social. São Paulo: Atlas, 1999.

HUDSON, M. Introducing integrated performance measurement into small and medium sized enterprises. 2001. 189p. Tese (Doutorado) - Plymouth Business School, University of Plymouth.

HUMPHREY, J. Opportunities for SME's in developing countries to upgrade in a global economy. International Labour Office, n. 43, 2003. (working paper).

HUMPHREY, J.; SCHMITZ, H. Governance and upgrading in global value chains. In: Governance and Upgrading: Linking Industrial Cluster and Global Value Chain Research. Brighton: University of Sussex, Aug. 2000. 22 p. (working paper).

INSTITUTO BRASILEIRO DE GEOGRAFIA E ESTATÍSTICA - IBGE. Classificação nacional de atividades econômicas. Rio de Janeiro, 2003.

KAPLAN, R. S.; NORTON, D. P. Using the balanced scorecard as a strategic management system. Harvard Business Review, v. 74, n. 1, p. 75-85, Jan./Feb. 1996.

Transforming the balanced scorecard from performance measurement strategic management: part I. Accouting Horizons, v. 15, n. 1, p. 87-104, Mar. 2001.

KAYDOS, W. Performance measurement and performance management. In: Measuring, managing, and maximizing performance. Portland: OR, Productivity Press, 1991. Cap. 3, p. 33-52.
KRUGMAN, P. Geography and trade. Cambridge: MIT, 1991. Cap. 2, p. 35-54.

LAITINEN, E. A dynamic performance measurement system: evidence from small finnish technology companies. Scandinavian journal of management, v. 18, n.1, p. 65-99, 2002. Disponível em:<http://www.sciencedirect.com/science/ journal/09565221>. Acesso em: 12 Set. 2005

LEBAS, M. J. Performance measurement and performance management. International Journal Production Economics, v. 41, n. 23-25, p. 23-35, 1995.

LEHTINEN, E.; SMOLANDER, A.; TARVAINEN, K. Development of performance measurement system for management and continuous improvement. In: NEELY, A.; WAGGONER, D. B. (Eds.). Performance measurement: theory and practice. Cambridge: University of Cambridge, v. II, p.600-606, Jul., 1998.

MARTINS, R.A. The use of performance measurement information as a drive in designing a performance measurement system. In: PERFORMANCE MEASUREMENT AND MANAGEMENT CONFERENCE, 3, 2002, World Trade Centre. Proceedings... Boston: Performance Measurement Association, p. 371-378, 2002

. Sistemas de medição de desempenho: um modelo para a estruturação do uso. São Paulo, 1999. 248p. Tese (Doutorado) - Escola Politécnica, Universidade de São Paulo.

MENDES, M. L. Como vencer o desafio de crescer. Exame, p. 12-20, Out. 2005.

MEYER-STAMER, J. Estratégia de desenvolvimento local e regional: clusters, política de localização e competitividade sistêmica. [S.L.]: ILDES, Friedrich Ebert Stiftung, Set. 2001. Policy Paper, n. 28, p. 1-26.

MUSCAT, A. R. N.; FLEURY, A. C. C. Indicadores de qualidade e produtividade na indústria brasileira. Revista de Indicadores da Qualidade e Produtividade, v. 1, n. 1, p. 83-107, Fev. 1992.

NACIONES UNIDAS. Promoción y mantenimiento de agrupaciones y redes para el fomento de las PYMES. In: Reunión de expertos en establecimiento de agrupaciones y redes para el fomento de la Pequeña y la Mediana Empresa (PYMES). Genebra: UNCTAD, 1998. Documento de debate elaborado pela secretaría. Disponível em: $<$ http://www.unctad. org/sp/docs/c3em5d2.sp.pdf>. Acesso em: 12 Mar. 2005.

NEELY, A. Measuring business performance. London: The Economics, 1998. Cap. 3, p. 70-89.

NEELY, A.; ADAMS, C. Perspectives on performance: the performance prism. Cranfield: Center for Business Performance, 2001. (working paper, 7 p.).

NEELY, A.; GREGORY, M.; PLATTS, K. Performance measurement system design - a literature review and research agenda. International Journal of Operations \& Production Management, v. 5, n. 4, p. 80-116, 1995.

NEELY, A. et al. Designing performance measures: a structured approach. International Journal of Operations \& Production Management, v. 17, n. 11, p. 1131-1152, 1997.

NORREKLIT, H. The balance on the balanced scorecard - a critical analysis of some of its assumptions. Management Accounting Research, v. 11, n. 1, p. 65-88, 2000.

OIKO, O. T. Desenvolvimento de um sistema de informação para benchmarking e sua aplicação em Arranjos Produtivos Locais. São Carlos, 2007. 183p. Dissertação (Mestrado) - Escola de Engenharia de São Carlos, Universidade de São Paulo.

OLAVE, M. E. L.; AMATO NETO, J. Geração e difusão do conhecimento nos clusters de economias emergentes. [S.L.]: [s.n.], 2000. (Texto disponível na pasta de aula do Prof. João Amato Neto, USP/EP, 8p.).

PORTER, M. Clusters and the new economics of competition. Harvard Business Review, v. 76, n. 6, p. 77-90, Nov./Dec. 2000.

PUGA, F. P. Alternativas de apoio a MPMES localizadas em arranjos produtivos locais. [S.L.]: BNDES, 2003. (Texto para 
discussão, n. 99). Disponível em:<http://redeincubar.anprotec. org.br:8280/portal/baixaFcdAnexo.do?id=6>. Acesso em: 12 Nov. 2004

PYKE, F. Promoción de las empresas mediante el establecimiento de redes de desarrollo regionales. [199?]. p. 1-10. (Monografia), Subdivisión de Políticas Industriales e Investigación, Naciones Unidas. Disponível em:<http://www. unctad.org>. Acesso em: 15 Out. 2004.

RENTES, A. F.; CARPINETTI, L. C. R.; Van AKEN, E. M. Measurement system development process: a pilot application andrecommendations. In:PERFORMANCEMEASUREMENT AND MANAGEMENT CONFERENCE, 3, 2002, World Trade Centre. Proceedings... Boston: Performance Measurement Association, p. 487-494, 2002.

ROESCH, S. M. A. Projetos de estágio e de pesquisa em administração: guia para estágios, trabalhos de conclusão, dissertações e estudos de caso. São Paulo: Atlas, 1999.

SANTOS, A. M. M. M.; GUARNERI, L. S. Características gerais do apoio e arranjos produtivos locais. Revista do BNDES, n. 12, p. 195-204, Set. 2000.

SCHMITZ, H. Collective efficiency: growth path for small-scalle industry. The Journal of Development Studies, v. 31, n. 4, p. 529-566, 1995.

SCHMITZ, H. Collective efficiency and increasing return. Cambridge Journal of Economics, v. 24, n. 4, p. 465-483, Jul. 1999. Disponível em: <http://proquest.umi.pwdweb>. Acesso em: 27 Ago. 2004.

SCHMITZ, H.; MUSYCK, B. Industrial districts in Europe: policy lessons for developing countries? World Development, v. 22, n. 6, p. 889-910, 1994

SCHNEIDERMAN, A. M. Why balanced scorecards fail. Journal of Strategic Performance Measurement, p. 6-10, Jan. 1999.
SERVIÇO BRASILEIRO DE APOIO ÀS MICROS E PEQUENAS EMPRESAS. Boletim estatístico de micro e pequenas empresas. Observatório SEBRAE. Disponível em:<http:// www.SEBRAEmg.com.br/Geral/visualizadorConteudo. aspx?Cod_areaconteudo+520 >. Acesso em: 2 Set. 2005.

SOUSA, S.; ASPINWALL, E.; RODRIGUES, A. Performance measurement in English small and medium enterprises: survey results. Benchmarking: an international journal, v. 13, n. 1-2, p. 120-134, 2006.

STORPER, M.; HARRISON, B. Flexibility, hierarchy an regional development: the changing structure of industrial production systems and their forms of governance in the 1990s. Research Policy, v. 20, n. 5, p. 407-422, Oct., 1991.

SUZIGAN, W. Aglomerações industriais, como focos de políticas. Revista de Economia Política, v. 21, n. 3, p. 28-39, Jul./Set. 2001.

SUZIGAN, W. et al. Clusters ou Sistemas locais de produção: mapeamento, tipologia e sugestões de políticas. Revista de Economia Política, v. 24, n. 3, p.543-562, Jul. 2004.

VAN AKEN, E. M.; KLEIM, S.; GROESBECK, R. Building better performance measurement systems. Virginia: Enterprise research Lab. Blacksburg, Virginia Tech, 2001. (workin paper).

VERSCHOORE, J. R. S. (Org.). Redes de cooperação: uma nova organização de pequenas e médias empresas no Rio Grande do Sul. Porto Alegre: FEE, 2004. p. 1-46.

WILLIAMSOM, O. E. The economic institutions of capitalism - firms, markets, relational contracting. NewYork: The Free Press, 1985

YIN, R. K. Estudo de caso, planejamento e método. Porto Alegre: Artmed, 2001. Cap. 2.

\section{Sobre os autores}

\section{Edwin Vladimir Cardoza Galdámez}

Departamento de Engenharia de Produção - Universidade Estadual de Maringá (UEM)

Av. Colombo, 5790, Jd. Universitário, CEP 87020-900, Maringá, PR, Brasil

e-mail: evcgaldamez@uem.br

\section{Luiz Cesar Ribeiro Carpinetti}

Departamento de Engenharia de Produção - Universidade de São Paulo/Escola de Engenharia de São Carlos (USP/EESC) Av. Trabalhador São Carlense, 400, CEP 13566-590, São Carlos, SP, Brasil

e-mail: carpinet@sc.usp.br

\section{Mateus Cecílio Gerolamo}

Departamento de Engenharia de Produção - Universidade de São Paulo/Escola de Engenharia de São Carlos (USP/EESC) Av. Trabalhador São Carlense, 400, CEP 13566-590, São Carlos, SP, Brasil

e-mail: mateus.gerolamo@gmail.com

Agradecimentos: Agradecemos o apoio dos empresários e dos agentes/coordenadores locais de inovação (SEBRAE, FIESP, SINDICOBI e SINDICALCCADO); aos avaliadores do artigo pelas recomendações sugeridas e à Coordenação de Aperfeiçoamento de Pessoal de Nível Superior (CAPES) e Fundação de Amparo à Pesquisa do Estado de São Paulo (FAPESP), Processo N.2004/08362-0, pela disponibilização de recursos financeiros. 